\title{
A discrepância de tamanho dentário, de Bolton, na oclusão normal e nos diferentes tipos de más oclusões, bem como sua relação com a forma de arco e o posicionamento dentário*
}

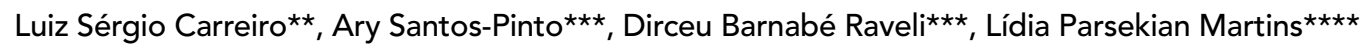

\section{Resumo}

Esta pesquisa teve como objetivo geral avaliar a discrepância de tamanho dentário, na oclusão normal e nos diferentes tipos de más oclusões e a sua relação com as medidas que determinam a forma de arco e o posicionamento dentário na região anterior. Para tanto, foram estudados 185 pares de modelos de gesso, divididos em 4 grupos: Grupo 1 (composto por 41 pares com Oclusão Normal, sendo 20 do gênero masculino e 21 do gênero feminino); Grupo 2 (composto por 44 pares com má oclusão de Classe I, divisão 1, sendo 22 do gênero masculino e 22 do gênero feminino); Grupo 3 (composto por 54 pares com má oclusão de Classe II, sendo 28 do gênero masculino e 26 do gênero feminino) e Grupo 4 (composto por 46 pares com Classe III, sendo 23 do gênero masculino e 23 do gênero feminino). Observou-se que não ocorreu dimorfismo sexual entre as discrepâncias de tamanho dentário e os diferentes tipos de oclusão dentária; as proporções estabelecidas por Bolton não se aplicaram ao grupo com Oclusão Normal; na Oclusão Normal, Classe I, Classe II e Classe III, houve um predomínio de excesso dentário total (RAZ12) no arco inferior; na Classe I houve uma igualdade na distribuição de excesso dentário anterior (RAZ6) nos arcos superior e inferior; na Oclusão Normal, Classe II e Classe III, ocorreu um predomínio de excesso dentário anterior (RAZ6) no arco inferior, em relação ao arco superior; os excessos dentários não contribuíram na ocorrência das más oclusões e as discrepâncias total e anterior (RAZ12 e RAZ6) não interferiram diretamente nas larguras e comprimentos dos arcos, bem como no posicionamento dos dentes anteriores.

Palavras-chave: Discrepância dentária. Dimensões de arco. Oclusão normal. Má oclusão. Irregularidade de incisivos.

\footnotetext{
* Resumo da Tese de Doutorado em Ortodontia (Faculdade de Odontologia de Araraquara - UNESP).

** Professor Adjunto em Ortodontia da Universidade Estadual de Londrina e da Universidade Norte do Paraná

*** Professor Adjunto do Departamento de Clínica Infantil-Ortodontia da Faculdade de Odontologia de Araraquara-UNESP.

$\star \star \star *$ Professora Assistente Doutora do Departamento de Clínica Infantil-Ortodontia da Faculdade de Odontologia de Araraquara - UNESP.
} 
INTRODUÇÃO E REVISÃO DE LITERATURA

Desde meados do Século XX as discrepâncias entre o tamanho mesiodistal dos dentes superiores e inferiores, bem como seus efeitos sobre a oclusão, têm sido relatados. Vários autores afirmaram que discrepâncias individuais ou em grupos de dentes podiam estar associadas ao surgimento de diastemas ou apinhamentos, falta de intercuspidação dos dentes, alterações na sobressaliência, na sobremordida e na curva de Spee $5,6,8,10,12,18,19,23,27,30,31,32,33,36,37$, 38,40,41. Deste modo, alguns estudos propuseram, a partir de análises de oclusões normais, proporções ideais entre o tamanho dos dentes superiores e inferiores $3,5,6,18,19,20,22$, sendo que o método proposto por Bolton ${ }^{5}$, tornou-se, inegavelmente, um dos mais difundidos e aceitos no meio ortodôntico, principalmente por se tratar de um recurso de fácil execução e aplicação $1,7,11,16,21,23,24,26,32,34,35,36,40,41$. Vários estudos foram realizados com o intuito de se verificar quais fatores poderiam estar associados às discrepâncias inter-arcos, como o dimorfismo sexual $1,2,4,8,9,15,21,25,32,35,41$ e a variação racial $1,11,15,21,25,32,35,39$, cujos resultados obtidos demonstraram uma falta de consenso entre os autores. Poucos estudos foram efetuados comparando-se a discrepância de tamanho dentário com os diferentes tipos de más oclusões e $^{1,7,11,15,16,21,33,35} \mathrm{e}$, do mesmo modo, não foi observado consenso nos resultados obtidos.

\section{PROPOSIÇÃO}

O objetivo geral desta pesquisa foi o de avaliar a discrepância de tamanho dentário nas diferentes oclusões dentárias e sua relação com os parâmetros que determinam a forma de arco e o posicionamento dentário na região anterior.

\section{MATERIAL E MÉTODO}

\section{Composição e critérios de seleção da amostra}

Foram avaliados 185 pares de modelos de gesso, sendo que os mesmos ficaram assim distribuídos: Grupo 1 (composto por 41 pares com oclusão normal, sendo 20 do gênero masculino e 21 do gênero feminino); Grupo 2 (composto por 44 pares com má oclusão de Classe I, sendo 22 do gênero masculino e 22 do gênero feminino); Grupo 3 (composto por 54 pares com má oclusão de Classe II, divisão 1, sendo 28 do gênero masculino e 26 do gênero feminino) e Grupo 4 (composto por 46 pares com Classe III, sendo 23 do gênero masculino e 23 do gênero feminino). A amostra foi obtida dos arquivos do Curso de Especialização em Ortodontia e Ortopedia Facial, da Universidade Estadual de Londrina, Estado do Paraná, e de arquivos particulares, de clínicas privadas. $\mathrm{O}$ critério utilizado para a classificação das más oclusões foi dentoesquelético e a avaliação dentária realizada por meio de modelos de estudo, utilizando-se a classificação de Angle que deveria coincidir com a avaliação esquelética, que por sua vez foi efetuada por meio de telerradiografias, onde a relação ântero-posterior das bases ósseas foi analisada pelo ângulo ANB (pacientes portadores de Classe I e com Oclusão Normal com ANB de 0 a $4^{\circ}$; pacientes portadores de Classe II com $\mathrm{ANB}>4^{\circ}$ e pacientes portadores de Classe III com $\mathrm{ANB}<-1^{\circ}$ ).

A amostra foi selecionada ao acaso, de pacientes leucodermas, de ambos os gêneros e na faixa etária dos 13 aos 23 anos, em fase inicial do tratamento, onde nenhum procedimento clínico-terapêutico havia sido efetuado. Como critério básico para inclusão na amostra os modelos deveriam apresentar todos os dentes permanentes (de primeiros molares a primeiros molares do lado oposto, em ambos os arcos) e foram eliminados aqueles que apresentaram dentes decíduos, ausência de algum dente permanente, dentes com grandes mutilações, dentes com restaurações inadequadas, dentes em estágio eruptivo e mal posicionados, onde não foi possível uma determinação adequada dos pontos e indivíduos que não eram leucodermas.

\section{Obtenção dos dados}

Após a devida calibração do aparelho e do operador foi iniciado o processo de obtenção dos dados.

Foram digitalizados pontos pré-determinados nos modelos de gesso, nos arcos superiores e inferiores, utilizando-se como instrumento de medi- 
ção o "Digitalizador Tridimensional Microscribe3DX" (Fig. 1), sendo que houve um intervalo de descanso do operador a cada 5 pares de modelos aferidos.

Registrou-se os pontos mais externos das faces proximais do primeiro molar ao primeiro molar do lado oposto, totalizando-se 12 dentes, em ambos os arcos.

Também foram digitalizados os pontos centrais das cúspides dos caninos superiores e inferiores, bem como foi determinado um ponto "construído" (PC), que representou o centro dos primeiros molares superiores e inferiores, e que foi obtido pela média de 4 pontos digitalizados na superfície oclusal de cada dente (Fig. 2A, B).

Os valores obtidos foram transferidos direta-

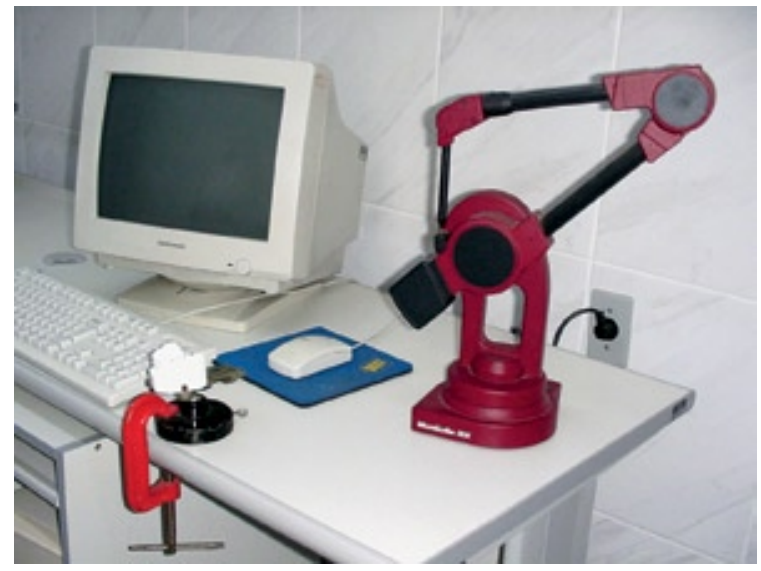

FIGURA 1 - Digitalizador Tridimensional Microscribe-3DX, posicionador de modelos e periféricos.

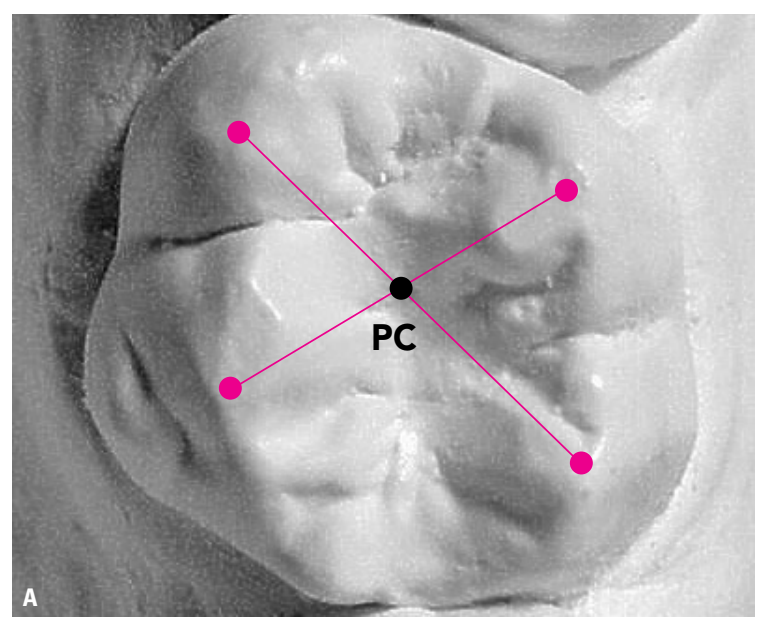

mente para uma planilha do "software Excell (Microsoft)", na forma de coordenadas X, Y e Z, para que não houvesse interferência e possibilidade de erro durante a leitura das medidas.

A partir destas coordenadas foram determinadas as dimensões mesiodistais dos incisivos centrais, incisivos laterais, caninos, primeiros pré-molares, segundos pré-molares e primeiros molares, em ambos os arcos e bilateralmente.

Determinou-se a distância intercaninos (3-3), cujo objetivo foi analisar as larguras anterior superior (LASUP) e anterior inferior (LAINF) dos arcos, bem como serviu como referência para a obtenção dos comprimentos anterior superior (CASUP) e anterior inferior (CAINF) dos mesmos (Fig. 3).

Os quatro pontos digitados em cada face oclusal dos primeiros molares superiores e inferiores serviram como referência para se determinar os pontos centrais de cada molar. A partir destes pontos centrais obteve-se a distância intermolares, cujo objetivo foi analisar as larguras posterior superior (LPSUP) e posterior inferior (LPINF) dos arcos, bem como serviu como referência para a obtenção dos comprimentos posterior superior (CPSUP) e posterior inferior (LPINF) dos mesmos (Fig. 4).

As distâncias entre os pontos de contato adjacentes dos quatro incisivos e dos incisivos laterais com os pontos de contato das faces mesiais dos caninos inferiores foram registradas, para se de-

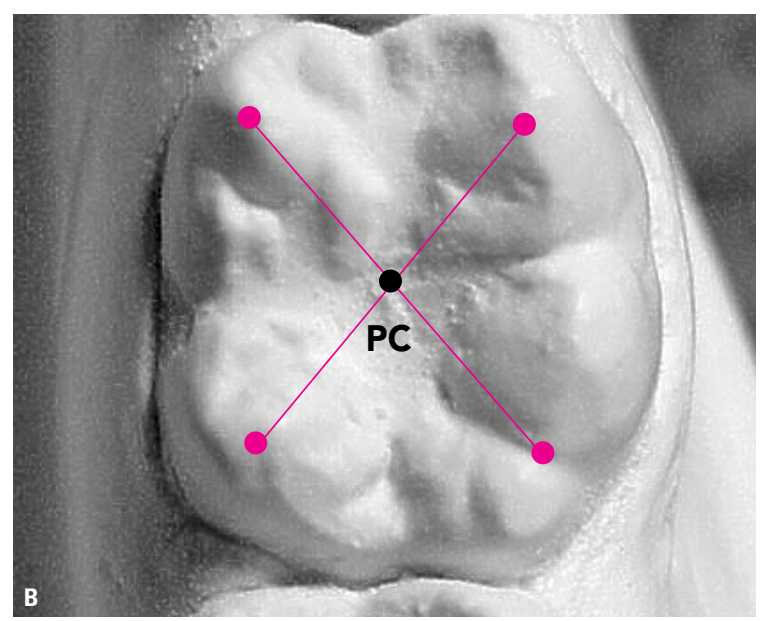

FIGURA 2 - Pontos digitalizados nas superfícies oclusais do primeiro molar superior direito (A), inferior direito (B) e ponto construído (PC). 
terminar o Índice de Irregularidade, proposto por Little $^{17}$, com o intuito de se quantificar o grau de apinhamento na região anterior superior (IIRSUP) e inferior (IIRINF) (Fig. 5).

Em função do Digitalizador Tridimensional Microscribe-3DX utilizar três coordenadas (X, Y e Z), optou-se também pela determinação de um Índice de Irregularidade "corrigido" superior (IIRCSUP) e inferior (IIRCINF), onde a coordenada vertical foi suprimida, eliminando quaisquer interferências desta nos valores.

De posse destes dados, aplicou-se a análise proposta por Bolton ${ }^{5}$, onde são determinadas inicialmente o somatório dos diâmetros mesiodistais dos dentes anteriores inferiores, dos dentes anteriores superiores, somatório total dos diâmetros mesiodistais dos dentes inferiores (do primeiro molar ao primeiro molar do lado oposto) e total dos dentes superiores (do primeiro molar ao primeiro molar do lado oposto). Seguindo seus preceitos, aplicouse as fórmulas preconizadas, tanto para o segmen-

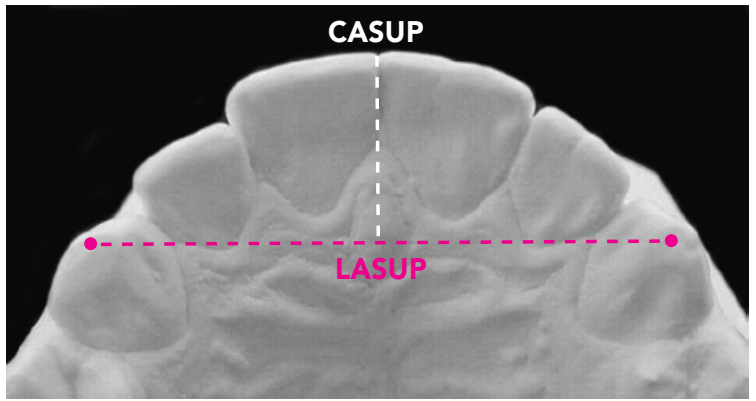

FIGURA 3 - Largura e comprimento anterior do arco superior (LASUP e CASUP).

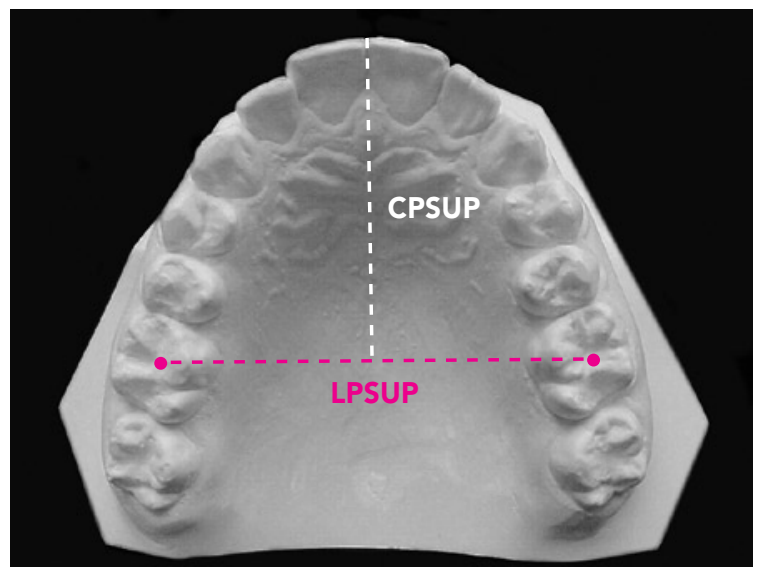

FIGURA 4 - Largura e comprimento posterior do arco superior (LPSUP e CPSUP). to anterior, como para todo o arco, determinando assim a razão anterior (RAZ6), definida pela proporção entre os 6 dentes anteriores inferiores pelo superiores, bem como a razão total (RAZ12), definida pela proporção entre os 12 dentes (do primeiro molar ao primeiro molar do lado oposto) inferiores pelo superiores.

\section{Verificação do erro de digitalização (Reprodu- tibilidade das medidas)}

Com o intuito de verificar o erro de digitalização dos pontos, foram redigitalizados 18 pares de modelos, escolhidos aleatoriamente, de forma a representar $10 \%$ do total da amostra. Estes modelos foram redigitalizados pelo mesmo operador após 5 meses, mantendo-se as condições iniciais de trabalho.

\section{Hipóteses testadas}

Os objetivos delineados na presente pesquisa sugerem vários questionamentos ou hipóteses:

1) O pesquisador foi capaz de reproduzir as medidas utilizadas em sua pesquisa?

2) Nos diferentes tipos de más oclusões ocorre dimorfismo sexual, em relação à discrepância de tamanho dentário ou em relação às medidas de forma de arco e posicionamento dentário?

3) Há relação entre discrepância de tamanho dentário com a oclusão normal e os diferentes tipos de más oclusões?

4) O perfil da discrepância de tamanho dentário, em cada grupo de oclusão dentária, foi o mesmo, segundo as condições de normalidade e de não normalidade?

5) Cada uma das medidas da discrepância de

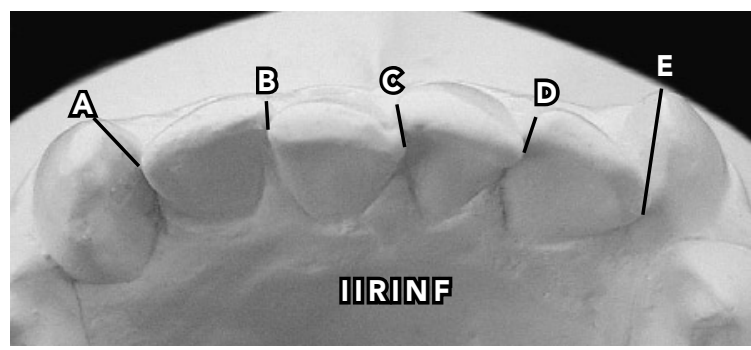

FIGURA 5 - IIRINF: Índice de Irregularidade de Little ${ }^{17}$. 
tamanho dentário (RAZ12 e RAZ6) pode ser expressa como uma função linear das medidas que determinam a forma do arco e o posicionamento dentário?

\section{RESULTADOS}

\section{Calibração do pesquisador}

A análise dos dados obtidos na redigitalização dos 18 pares de modelos mostrou que o pesquisador estava calibrado quanto à realização das mensurações efetuadas nesta pesquisa. Os coeficientes de determinação $\left(R^{2}\right)$ associados a cada uma das medidas foram relevantes, pois verificou-se que o modelo explicou pelo menos $71 \%$ da variação dos dados obtidos na segunda digitação.

Utilizando modelo de regressão linear e teste de Bartlett, para verificar a hipótese de homocedasticidade, constatou-se que o pesquisador cometeu somente o erro casual nas mensurações de cada medida com a mesma precisão, porque as variâncias associadas a cada erro foram estatisticamente iguais entre si.

\section{Influência dos gêneros sobre as medidas, em cada grupo de oclusão}

As médias obtidas para o gênero feminino foram estatisticamente iguais às obtidas no gênero masculino. Somente entre as dimensões do arco dentário (comprimento e largura) é que houve um aumento significante para o gênero masculino. Entretanto, estas medidas não foram utilizadas diretamente em comparação às razões anterior e posterior.

\section{Relação entre os grupos de oclusão dentária, para todas as medidas}

Os valores $\mathrm{F}_{0}$ relativos às medidas RAZ12, CASUP, LAINF, LPSUP e LPINF não foram significantes, o que implicou que os grupos de oclusão induziram efeitos iguais sobre essas medidas, isto é, cada uma dessas medidas apresentou médias iguais nos quatro tipos de oclusão dentária. A tabela 2 apresentou essas médias, estatisticamente iguais entre si e pertencentes à mesma classificação A, para cada uma dessas medidas.
Os valores $\mathrm{F}_{0}$ relativos às medidas RAZ6, CPINF, CPSUP, CAINF, LASUP, IIRSUP, IIRINF, IIRCSUP e IIRCINF foram significantes. Assim, para cada uma dessas medidas, a hipótese igualdade entre as médias nos grupos de oclusão foi rejeitada. As médias relativas a cada uma dessas medidas encontram-se na tabela 2 assim como a classificação correspondente.

$\mathrm{Na}$ tabela 2, verificou-se que:

- na medida RAZ6, o grupo com Oclusão Normal apresentou média estatisticamente igual à do grupo com Classe I (classificação A) e menor do que as apresentadas pelos grupos com Classe II e Classe III;

- na medida CPSUP, a única diferença evidente ocorreu entre o grupo de Oclusão Normal (classificação A) e o grupo com Classe II (classificação C);

- na medida CPINF, o grupo com Classe III apresentou média estatisticamente igual à do grupo com Classe II (classificação B) e menor do que as apresentadas pelos grupos com Classe I e Oclusão Normal;

- na medida CAINF, a única diferença evidente ocorreu entre o grupo com Oclusão Normal

\begin{tabular}{|c|c|c|}
\hline \multicolumn{3}{|c|}{ Tabela 1 - Resumo da análise de variância para a hipótese } \\
sobre os grupos com má oclusão e oclusão normal. \\
\hline Medida & $\mathbf{F}_{\mathrm{o}}$ & $\mathbf{P}<$ \\
\hline RAZ12 & $0,459 \mathrm{n}$ & 0,711 \\
\hline RAZ6 & $5,077 \mathrm{~s}$ & 0,002 \\
\hline CPSUP & $13,468 \mathrm{~s}$ & 0,001 \\
\hline CPINF & $7,654 \mathrm{~s}$ & 0,001 \\
\hline CASUP & $1,785 \mathrm{n}$ & 0,152 \\
\hline CAINF & $4,134 \mathrm{~s}$ & 0,007 \\
\hline LASUP & $5,483 \mathrm{~s}$ & 0,001 \\
\hline LAINF & $2,143 \mathrm{n}$ & 0,096 \\
\hline LPSUP & $1,635 \mathrm{n}$ & 0,183 \\
\hline LPINF & $2,401 \mathrm{n}$ & 0,069 \\
\hline IIRSUP & $31,592 \mathrm{~s}$ & 0,001 \\
\hline IIRINF & $14,465 \mathrm{~s}$ & 0,001 \\
\hline IIRCSUP & $27,615 \mathrm{~s}$ & 0,001 \\
\hline IIRCINF & $9,948 \mathrm{~s}$ & 0,001 \\
\hline
\end{tabular}

$\mathrm{s}=$ valor significante; $\mathrm{n}=$ valor não significante. 
Tabela 2 - Freqüências, médias, desvios-padrão e classificação (Tukey) para as medidas, segundo cada grupo de má oclusão e oclusão normal (mm).

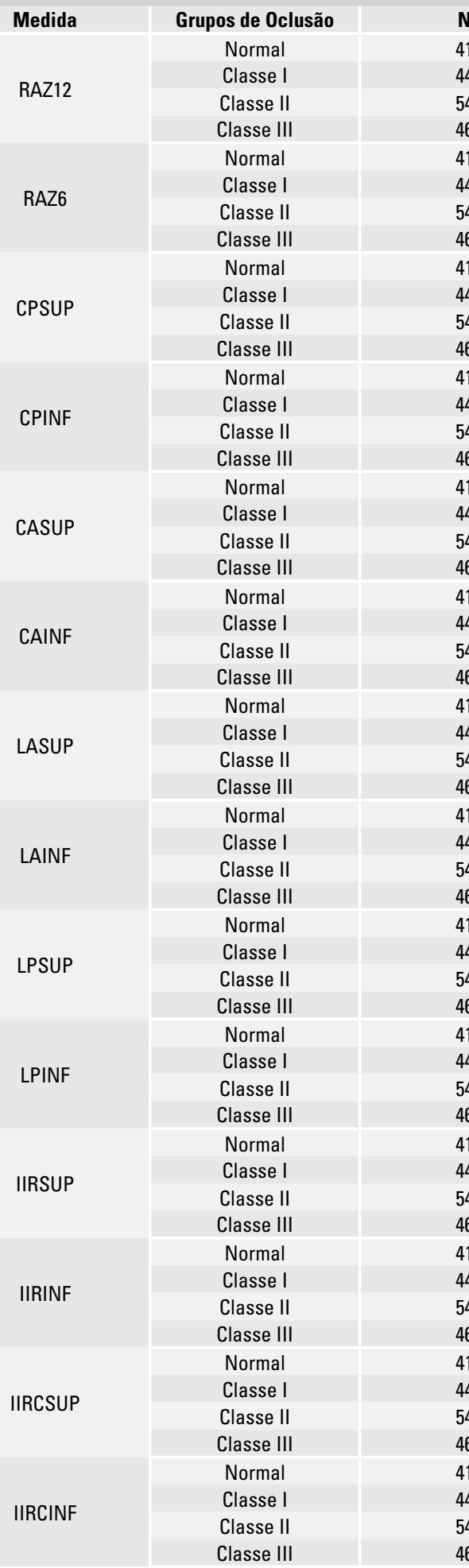

\begin{tabular}{|l|l|}
\hline $\mathbf{N}$ \\
\hline 41 \\
\hline 44 \\
\hline 54 \\
\hline 46 \\
\hline 41 & \\
\hline 44 & \\
\hline 54 & \\
\hline 46 & \\
\hline 41 & \\
\hline 44 & \\
\hline 54 & \\
46 & \\
\hline 41 & \\
\hline 44 & \\
\hline
\end{tabular}

Média

91,76

92,13

92,24

92,30

78,24

77,14

79,79

79,54

30,58

33,74

32,39

31,24

26,41

28,59

27,5

26,65

7,95

8,58

8,46

7,92

4,63

5,22

5,50

4,81

34,53

35,99

34,02

34,47

25,82

26,81

26,59

26,73

48,15

47,89

47,48

48,91

41,86

41,80

42,39

43,37

3,84

10,66

8,66

7,91

3,42

7,27

6,25

5,36

2,84

8,15

6,62

5,83

2,61

4,84

4,45

3,70

\section{Desvio-Padrão}

2,51

2,08

2,56

2,69

3,40

3,15

4,24

4,46

2,30

2,49

3,05

1,61

2,14

2,22

2,49

3,51

1,43

2,18

1,62

1,58

1,22

1,22
1,31

1,31
1,54

1,75

1,75

3,14

2,70

2,59

1,61

2,17

2,21

2,03

2,31

3,12

3,29

4,68

2,25

2,80

3,13

5,70

2,21

3,91

3,59

2,03

2,17

3,39

3,06

3,31

2,08

3,51

3,49

2,97

2,76

3,81

2,28

3,12
Classificação

$A$

A

A

A, B

A

B

B

A

C

B,B

A

B

A,B

A

A

A

A

A

A

A, B

$B$

A,B

A

A

A

A

A

A

A

A

A

A

A

A

A

A

A

A

C

B

B

A

$B, C$

B

A

C

B

B

A

B,C
$A, B$ 
(classificação A) e o grupo com Classe II (classificação B);

- na medida LASUP, o grupo com Classe III apresentou a maior média (classificação B) e os demais grupos apresentaram médias estatisticamente iguais entre si (classificação A);

- na medida IIRSUP, os grupos com Classe I e Classe II apresentaram médias iguais entre si e maiores (classificação B), o grupo com Oclusão Normal a menor (classificação A), situando-se o grupo com Classe II numa posição intermediária (classificação C);

- na medida IIRINF, o grupo com Oclusão Normal apresentou a menor média (classificação A).

\section{Estudo das freqüências de não normalidade e de normalidade da discrepância dentária}

O estudo da hipótese de igual ocorrência de freqüência de valores da discrepância do tamanho dentário, nas condições de normalidade e de não normalidade, foi realizado com o auxílio da estatística de quiquadrado $\left(\chi^{2}\right)$ e dos dados constantes da tabela 3.

A hipótese de igualdade entre as freqüências relativas das condições de não normalidade aquém e além da média e da de normalidade foi rejeitada, após a aplicação da estatística de quiquadrado com dois graus de liberdade, tanto para a RAZ12 como para a RAZ6 em cada tipo de oclusão dentária. Os valores da estatística de quiquadrado apresentados na tabela 7 referem-se ao teste adicional para a significância às freqüências relativas numericamente mais próximas, pois a indagação que se fez presente foi a de que: como as três freqüências, observadas em cada razão e em cada tipo de oclusão dentária, mostraram-se estatisticamente diferentes entre si, o mesmo ocorreu com as que se apresentaram numericamente próximas?

$\mathrm{Na}$ tabela 3, verificou-se que:

- na Oclusão Normal, as freqüências de não normalidade foram estatisticamente iguais entre si $(p>0,05)$ e menores do que a de normalidade para a RAZ12, enquanto que na RAZ6 a freqüência de não normalidade aquém da média foi me- nor do que a de não normalidade além da média $(\mathrm{p}<0,05)$, que foi menor do que a de normalidade;

- na má oclusão de Classe I, na RAZ12 a freqüência de não normalidade aquém da média foi menor do que a de não normalidade além da média $(\mathrm{p}<0,05)$, que foi menor do que a de normalidade, enquanto que na RAZ6, as freqüências de não normalidade foram estatisticamente iguais entre si ( $p>0,05$ ) e menores do que a de normalidade;

- na má oclusão de Classe II, na RAZ12 as freqüências de não normalidade foram estatisticamente iguais entre si $(p>0,05)$ e menores do que a de normalidade, enquanto que na RAZ6 as freqüências de normalidade e de não normalidade além da média foram estatisticamente iguais entre si $(p>0,05)$ e maiores do que a da condição de não normalidade aquém da média;

- na má oclusão de Classe III, na RAZ12 as freqüências de não normalidade foram estatisticamente iguais entre si $(\mathrm{p}>0,05)$ e menores do que a de normalidade, enquanto que na RAZ6 as freqüências de normalidade e de não normalidade além da média foram estatisticamente iguais entre si $(p>0,05)$ e maiores do que a da condição de não normalidade aquém da média.

\section{Avaliação se as medidas RAZ12 e RAZ6 po- dem ser expressas como uma função linear de medidas que determinam a forma do arco e o posicionamento dentário na região anterior}

A aplicação do modelo de regressão linear aos dados obtidos de RAZ12 e das outras medidas, originou a tabela 4 , em que as notações $B_{0}$ e $B_{1}$ referem-se às estimativas dos parâmetros $\beta_{0}$ e $\beta_{1}$ do modelo (I), respectivamente.

$\mathrm{Na}$ tabela 4, verificou-se que:

- a medida RAZ12 não pôde ser expressa como uma função linear de nenhuma das outra medidas adotadas nesse estudo porque o coeficiente de determinação $\left(\mathrm{R}^{2}\right)$, que explicou, a partir do modelo de regressão linear, a variação ocorrida nos valores obtidos para RAZ12, foi inexpressivo para cada uma das outras medidas. De fato, o maior valor obtido para $\mathrm{R}^{2}$ foi 0,056 para a medida CPINF, o que significou que o modelo que expressou 


\begin{tabular}{|c|c|c|c|c|c|c|c|}
\hline \multirow[b]{2}{*}{ Oclusão } & \multirow[b]{2}{*}{ Condição } & \multicolumn{3}{|c|}{ RAZ12 } & \multicolumn{3}{|c|}{ RAZ6 } \\
\hline & & Valores & FA & FR (\%) & Valores & FA & FR $(\%)$ \\
\hline \multirow{5}{*}{ Normal } & N.Normalidade & 84,02 ou menos & 1 & 2,4 & 73,78 ou menos & 2 & 4,9 \\
\hline & Normalidade & De 88,53 a 94,97 & 35 & 84,4 & De 74,30 a 80,36 & 30 & 73,1 \\
\hline & N.Normalidade & 95,66 ou mais & 5 & 13,2 & 80,47 ou mais & 9 & 22 \\
\hline & & Total & 41 & 100,0 & Total & 41 & 100,0 \\
\hline & & \multicolumn{3}{|c|}{$\chi^{2}(1)=2,877 n$, pois $p>0,089$} & \multicolumn{3}{|c|}{$\chi^{2}(1)=5,145$ s, pois $p<0,024$} \\
\hline \multirow{5}{*}{ CLI } & N.Normalidade & Não ocorreu & 0 & 0,0 & 73,77 ou menos & 7 & 15,9 \\
\hline & Normalidade & De 88,67 a 94,96 & 39 & 88,6 & De 74,67 a 79,97 & 30 & 68,2 \\
\hline & N.Normalidade & 95,01 ou mais & 5 & 11,4 & 80,61 ou mais & 7 & 15,9 \\
\hline & & Total & 44 & 100,0 & Total & 44 & 100,0 \\
\hline & & \multicolumn{3}{|c|}{$\chi^{2}(1)=5,301 \mathrm{~s}$, pois $p<0,022$} & \multicolumn{3}{|c|}{$\chi^{2}(1)=0,0 n$, pois $p>0,999$} \\
\hline \multirow{5}{*}{ CL II } & N.Normalidade & 87,04 ou menos & 2 & 3,7 & 73,58 ou menos & 4 & 7,4 \\
\hline & Normalidade & De 87,97 a 95,00 & 44 & 81,5 & De 74,17 a 79,65 & 24 & 44,5 \\
\hline & N.Normalidade & 95,09 ou mais & 8 & 14,8 & 80,61 ou mais & 26 & 48,1 \\
\hline & & Total & 54 & 100,0 & Total & 54 & 100,0 \\
\hline & & \multicolumn{3}{|c|}{$\chi^{2}(1)=0,787 n$, pois $p>0,374$} & \multicolumn{3}{|c|}{$\chi^{2}(1)=0,149 n$, pois $p>0,699$} \\
\hline \multirow{5}{*}{ CL. III } & N.Normalidade & 87,98 ou menos & 1 & 2,2 & 73,44 ou menos & 4 & 8,9 \\
\hline & Normalidade & De 87,61 a 97,70 & 39 & 86,7 & De 74,09 a 80,29 & 21 & 46,7 \\
\hline & N.Normalidade & 95,18 ou mais & 5 & 11,1 & 80,53 ou mais & 20 & 44,4 \\
\hline & & Total & 45 & 100,0 & Total & 45 & 100,0 \\
\hline & & \multicolumn{3}{|c|}{$\chi^{2}(1)=2,857 n$, pois $p>0,090$} & \multicolumn{3}{|c|}{$\chi^{2}(1)=0,045 n$, pois $p>0,832$} \\
\hline
\end{tabular}

RAZ12 como função de CPINF explicou somente $5,6 \%$ da variação ocorrida nos valores de RAZ12.

A aplicação do modelo de regressão linear aos dados obtidos de RAZ6 e das ouras medidas, originou a tabela 5 , aonde as notações $\mathrm{B}_{0}$ e $\mathrm{B}_{1}$ referemse às estimativas dos parâmetros $\beta_{0}$ e $\beta_{1}$ do modelo (I), respectivamente.

Na tabela 5, verificou-se que:

- a medida RAZ6 não pôde ser expressa como uma função linear de nenhuma das outra medidas adotadas nesse estudo porque o coeficiente de determinação $\left(\mathrm{R}^{2}\right)$, que explicou, a partir do modelo de regressão linear, a variação ocorrida nos valores obtidos para RAZ6, foi inexpressivo para cada uma das outras medidas. De fato, o maior valor obtido para $\mathrm{R}^{2}$ foi 0,043 para a medida CPSUP, o que significou que o modelo que expressou RAZ6 como função de CPSUP explicou somente $4,3 \%$ da variação ocorrida nos valores de RAZ12.

\section{DISCUSSÃO}

Com o intuito de facilitar e agrupar as diferentes abordagens e questionamentos deste estudo, a discussão do mesmo será efetuada em tópicos distintos.

\section{Obtenção das medidas}

A digitalização dos pontos, nos modelos de gesso, foi efetuada com o "Digitalizador Tridimensional Microscribe-3DX", cujo aparelho possibilita uma grande precisão no registro das medidas, bem como diminui a possibilidade da interferência do operador, uma vez que a cada ponto digitado os valores obtidos são transferidos diretamente para uma planilha do "software Excell (Microsoft)", na forma de coordenadas X, Y e Z, impedindo a interferência e possibilidade de erro durante a leitura das medidas. Hunter, Priest ${ }^{13}$ e Shellhart et al. ${ }^{29}$ compararam dois métodos de aferição, comumen- 


\begin{tabular}{|c|c|c|c|c|c|c|c|}
\hline Medida & Estimativas & E.P. & $t_{0}$ & $\mathbf{p}<$ & $F_{0}$ & $\mathbf{p}<$ & $\mathbf{R}^{2}$ \\
\hline \multirow{2}{*}{ CPSUP } & $B_{0}=24,05$ & 7,84 & $3,04 \mathrm{~s}$ & 0,002 & \multirow{2}{*}{$1,03 n$} & \multirow{2}{*}{0,314} & \multirow{2}{*}{0,006} \\
\hline & $B_{1}=0,09$ & 0,09 & $1,16 n$ & 0,314 & & & \\
\hline \multirow{2}{*}{ CPINF } & $B_{0}=4,29$ & 7,00 & $0,61 \mathrm{n}$ & 0,541 & \multirow{2}{*}{$10,85 \mathrm{~s}$} & \multirow{2}{*}{0,001} & \multirow{2}{*}{0,056} \\
\hline & $B_{1}=0,25$ & 0,08 & $3,29 \mathrm{~s}$ & 0,001 & & & \\
\hline \multirow{2}{*}{ CASUP } & $B_{0}=9,99$ & 4,98 & $2,01 \mathrm{~s}$ & 0,047 & \multirow{2}{*}{$0,12 \mathrm{n}$} & \multirow{2}{*}{0,726} & \multirow{2}{*}{0,001} \\
\hline & $B_{1}=0,02$ & 0,05 & $-0,35 n$ & 0,726 & & & \\
\hline \multirow{2}{*}{ CAINF } & $B_{0}=-1,80$ & 3,89 & $-0,46 n$ & 0,646 & \multirow{2}{*}{$3,12 \mathrm{n}$} & \multirow{2}{*}{0,079} & \multirow{2}{*}{0,017} \\
\hline & $B_{1}=0,07$ & 0,04 & $1,77 n$ & 0,079 & & & \\
\hline \multirow{2}{*}{ LASUP } & $\mathrm{B}_{0}=20,23$ & 7,33 & $2,76 \mathrm{~s}$ & 0,006 & \multirow{2}{*}{$3,91 \mathrm{~s}$} & \multirow{2}{*}{0,490} & \multirow{2}{*}{0,021} \\
\hline & $B_{1}=0,16$ & 0,08 & $1,98 \mathrm{~s}$ & 0,050 & & & \\
\hline \multirow{2}{*}{ LAINF } & $B_{0}=14,10$ & 5,77 & $2,44 \mathrm{~s}$ & 0,016 & \multirow{2}{*}{$4,63 \mathrm{~s}$} & \multirow{2}{*}{0,034} & \multirow{2}{*}{0,025} \\
\hline & $B_{1}=0,14$ & 0,06 & $2,15 \mathrm{~s}$ & 0,034 & & & \\
\hline \multirow{2}{*}{ LPSUP } & $\mathrm{B}_{0}=34,99$ & 9,41 & $3,72 \mathrm{~s}$ & 0,001 & \multirow{2}{*}{$1,94 \mathrm{n}$} & \multirow{2}{*}{0,167} & \multirow{2}{*}{0,011} \\
\hline & $B_{1}=0,14$ & 0,11 & $1,39 n$ & 0,167 & & & \\
\hline \multirow{2}{*}{ LPINF } & $\mathrm{B}_{0}=22,10$ & 8,99 & $2,46 \mathrm{~s}$ & 0,016 & \multirow{2}{*}{$5,08 \mathrm{~s}$} & \multirow{2}{*}{0,026} & \multirow{2}{*}{0,027} \\
\hline & $B_{1}=0,22$ & 0,10 & $2,25 \mathrm{~s}$ & 0,026 & & & \\
\hline \multirow{2}{*}{ IIRSUP } & $B_{0}=-21,82$ & 11,51 & $-1,90 n$ & 0,060 & $66 \mathrm{~s}_{\mathrm{s}}$ & & \\
\hline & $B_{1}=0,32$ & 0,12 & $2,58 \mathrm{~s}$ & 0,012 & $6,60 \mathrm{~s}$ & 0,012 & 0,035 \\
\hline JPINIF & $B_{0}=-11,66$ & 8,88 & $-1,31 n$ & 0,191 & 200 & & 0 010 \\
\hline minivr & $B_{1}=0,19$ & 0,10 & $1,95 \mathrm{n}$ & 0,054 & $0,00 \mathrm{II}$ & 0,034 & 0,010 \\
\hline IIRCSUP & $\mathrm{B}_{0}=91,38$ & 0,36 & $257,75 \mathrm{~s}$ & 0,001 & $581 \mathrm{~s}$ & 0.007 & 0.031 \\
\hline ImLour & $B_{1}=0,13$ & 0,05 & $2,41 \mathrm{~s}$ & 0,017 & 0 & 0,011 & (0,0 \\
\hline JPCINE & $\mathrm{B}_{0}=91,44$ & 0,36 & $256,27 \mathrm{~s}$ & 0,001 & $175 \mathrm{c}$ & 0031 & 0025 \\
\hline IIKLINFF & $\mathrm{B}_{1}=0,172$ & 0,08 & $2,18 \mathrm{~s}$ & 0,031 & $4,15 \mathrm{~s}$ & 0,031 & $0,0<5$ \\
\hline
\end{tabular}

$\mathrm{s}=$ valor significante; $\mathrm{n}=$ valor não significante.

te utilizados na Ortodontia, que são o paquímetro e o compasso de pontas secas e concluíram que o paquímetro apresentou maior freqüência de resultados repetidos, sendo mais confiável a sua utilização. Do mesmo modo, Schirmer e Wilshire ${ }^{28}$ afirmaram que o paquímetro é a melhor forma de se realizar análise de tamanho dentário.

\section{Dimorfismo sexual}

Vários estudos têm relatado a existência de diferenças significativas entre o tamanho de dentes de homens e mulheres, havendo uma tendência dos homens a apresentarem dentes maiores no sentido mesiodistal do que as mulheres $2,4,8,9,15,25,32$, embora Woodworth et al. ${ }^{41}$ tenham encontrado incisivos inferiores menores no gênero masculino e molares maiores que o normal no feminino.

Em virtude disso, a primeira avaliação desta pesquisa foi verificar se ocorre dimorfismo sexual dentro dos diferentes tipos de más oclusões, em relação à discrepância de tamanho dentário. Este procedimento objetivou determinar se poderíamos agrupar os gêneros dentro de cada grupo específico de má oclusão ou se haveria necessidade de uma avaliação separada, para evitar quaisquer possiveis interferências do gênero.

Dentro do grupo com Oclusão Normal, observou-se um valor próximo entre as médias obtidas 


\begin{tabular}{|c|c|c|c|c|c|c|c|}
\hline Medida & Estimativas & E.P. & $t_{0}$ & $\mathbf{p}<$ & $F_{0}$ & $p<$ & $\mathbf{R}^{2}$ \\
\hline \multirow{2}{*}{ CPSUP } & $B_{0}=43,61$ & 4,04 & $10,79 \mathrm{~s}$ & 0,001 & \multirow{2}{*}{$8,23 \mathrm{~s}$} & \multirow{2}{*}{0,005} & \multirow{2}{*}{0,043} \\
\hline & $B_{1}=-0,15$ & 0,05 & $-2,87 \mathrm{~s}$ & 0,005 & & & \\
\hline \multirow{2}{*}{ CPINF } & $B_{0}=26,59$ & 3,79 & $7,02 \mathrm{~s}$ & 0,001 & \multirow{2}{*}{$0,04 n$} & \multirow{2}{*}{0,844} & \multirow{2}{*}{0,001} \\
\hline & $B_{1}=0,009$ & 0,05 & $0,20 n$ & 0,844 & & & \\
\hline \multirow{2}{*}{ CASUP } & $\mathrm{B}_{0}=13,39$ & 2,59 & $5,18 \mathrm{~s}$ & 0,001 & \multirow{2}{*}{$3,97 \mathrm{~s}$} & \multirow{2}{*}{0,049} & \multirow{2}{*}{0,021} \\
\hline & $B_{1}=-0,07$ & 0,03 & $-1,99 \mathrm{~s}$ & 0,049 & & & \\
\hline \multirow{2}{*}{ CAINF } & $\mathrm{B}_{0}=1,68$ & 2,05 & $0,82 n$ & 0,413 & \multirow{2}{*}{$2,76 n$} & \multirow{2}{*}{0,099} & \multirow{2}{*}{0,015} \\
\hline & $B_{1}=0,04$ & 0,03 & $1,66 n$ & 0,099 & & & \\
\hline \multirow{2}{*}{ LASUP } & $B_{0}=41,17$ & 3,87 & $10,65 \mathrm{~s}$ & 0,001 & \multirow{2}{*}{$2,79 n$} & \multirow{2}{*}{0,096} & \multirow{2}{*}{0,015} \\
\hline & $B_{1}=-0,08$ & 0,05 & $-1,67 n$ & 0,096 & & & \\
\hline \multirow{2}{*}{ LAINF } & $B_{0}=24,41$ & 3,07 & $7,96 \mathrm{~s}$ & 0,001 & \multirow{2}{*}{$0,47 n$} & \multirow{2}{*}{0,495} & \multirow{2}{*}{0,003} \\
\hline & $B_{1}=0,03$ & 0,04 & $0,69 n$ & 0,495 & & & \\
\hline \multirow{2}{*}{ LPSUP } & $\mathrm{B}_{0}=45,74$ & 4,97 & $9,21 \mathrm{~s}$ & 0,001 & \multirow{2}{*}{$0,22 n$} & \multirow{2}{*}{0,639} & \multirow{2}{*}{0,001} \\
\hline & $B_{1}=0,03$ & 0,06 & $0,47 n$ & 0,639 & & & \\
\hline \multirow{2}{*}{ LPINF } & $\mathrm{B}_{0}=34,81$ & 4,76 & $7,31 \mathrm{~s}$ & 0,001 & \multirow{2}{*}{$2,52 \mathrm{n}$} & \multirow{2}{*}{0,114} & \multirow{2}{*}{0,014} \\
\hline & $B_{1}=0,10$ & 0,06 & $1,59 \mathrm{n}$ & 0,114 & & & \\
\hline \multirow{2}{*}{ IIRSUP } & $B_{0}=6,56$ & 6,16 & $1,07 n$ & 0,288 & $005 n$ & 0830 & 0001 \\
\hline & $B_{1}=0,02$ & 0,08 & $0,21 n$ & 0,830 & $0,0 J 11$ & 0,000 & 0,001 \\
\hline JIRINE & $\mathrm{B}_{0}=2,33$ & 4,71 & $0,50 n$ & 0,595 & $050 n$ & 0482 & 0003 \\
\hline mirvi & $B_{1}=0,04$ & 0,06 & $0,70 \mathrm{n}$ & 0,482 & 0,0011 & 0,402 & 0,000 \\
\hline UP CСUD & $\mathrm{B}_{0}=78,51$ & 0,59 & $133,98 \mathrm{~s}$ & 0,001 & 0 & 0900 & 0001 \\
\hline mincour & $B_{1}=0,04$ & 0,09 & $0,47 n$ & 0,638 & $0, \angle Z n$ & 0,038 & 0,001 \\
\hline IIRCINE & $\mathrm{B}_{0}=78,06$ & 0,59 & $133,31 \mathrm{~s}$ & 0,001 & $184 n$ & 0177 & م010 \\
\hline IInUtror & $B_{1}=0,18$ & 0,13 & $1,36 n$ & 0,177 & $1,04 \|$ & 0,17 & 0,010 \\
\hline
\end{tabular}

$\mathrm{s}=$ valor significante; $\mathrm{n}=$ valor não significante.

para a RAZ12 nos gêneros feminino e masculino, sendo $91,32 \%$ e $92,20 \%$, respectivamente, bem como um valor próximo entre as médias para a RAZ6, sendo $77,79 \%$ e 78,70\%, respectivamente, implicando a não ocorrência de dimorfismo sexual para estas medidas, tornando possível o agrupamento dos dois gêneros para as demais comparações. Com base nestes resultados pode-se afirmar que não ocorreram diferenças significantes na relação entre os dentes inferiores e superiores, tanto para a RAZ12 como para a RAZ6, entre os gêneros, não havendo necessidade de se realizar estudos separados dos mesmos.

Embora não tenham sido utilizadas como pa- râmetro para as outras comparações, as demais medidas analisadas na pesquisa também foram submetidas à análise de verificação da possível presença de dimorfismo sexual. Constatou-se que nos indivíduos portadores de Oclusão Normal os arcos dentários superiores foram mais largos, tanto na região anterior como na posterior e os arcos dentários inferiores foram mais largos apenas na região posterior, de modo significante, embora todas as demais medidas apresentaram-se aumentadas no gênero masculino, podendo-se concluir que é de se esperar a presença de arcos maiores, em todos os sentidos, no gênero masculino. A única medida que se apresentou aumentada no gênero 
feminino foi a quantidade de apinhamento na região ântero-inferior (Índice de Irregularidade de Little), embora sem significância estatística.

No grupo com má oclusão de Classe I, observou-se um valor próximo entre as médias obtidas para a RAZ12 nos gêneros feminino e masculino, sendo $91,86 \%$ e $92,39 \%$, respectivamente, bem como um valor próximo entre as médias para a RAZ6, sendo 77,03\% e 77,23\%, respectivamente, implicando a não ocorrência de dimorfismo sexual para estas medidas, tornando possível o agrupamento dos dois gêneros para as demais comparações.

Também nos portadores de má oclusão de Classe I os arcos dentários superiores foram mais largos na região anterior, de modo significante, embora todas as demais medidas apresentaram-se aumentadas no gênero masculino, conduzindo a uma conclusão de que é de se esperar uma tendência na presença de arcos maiores, em todos os sentidos. Em relação ao posicionamento dentário pode-se afirmar que ocorreu uma maior quantidade de apinhamento na região ântero-inferior (expresso pelo Índice de Irregularidade de Little) no gênero masculino, em portadores de Classe I.

Em relação ao grupo de Classe II, divisão 1, observou-se um valor próximo entre as médias obtidas para a RAZ12 nos gêneros feminino e masculino, sendo $91,27 \%$ e 92,13\%, respectivamente, bem como um valor próximo entre as médias para a RAZ6, sendo 79,73\% e 79,84\%, respectivamente, demonstrando a não ocorrência de dimorfismo sexual para estas medidas. Assim como na Classe I e no grupo normal, nos portadores de má oclusão de Classe II, divisão 1, os arcos dentários superiores e inferiores apresentaram um comprimento posterior total aumentado, de modo significante, no gênero masculino, bem como os arcos superiores e inferiores com as larguras anterior e posterior aumentadas, também de modo significante. Todas as demais medidas também apresentaram-se aumentadas, embora sem significância estatística, no gênero masculino, conduzindo a uma conclusão de que é de se esperar a presença de arcos maiores, em todos os sentidos, neste gênero, em portadores de má oclusão de Classe II.

Seguindo a mesma seqüência de averiguação, no grupo com má oclusão de Classe III observouse um valor próximo entre as médias obtidas para a RAZ12 nos gêneros feminino e masculino, sendo $91,85 \%$ e $92,82 \%$, respectivamente, bem como um valor próximo entre as médias para a RAZ6, sendo $79,12 \%$ e $80,02 \%$, respectivamente, implicando a não ocorrência de dimorfismo sexual para estas medidas. Observou-se que nos portadores de má oclusão de Classe III os arcos dentários inferiores apresentaram um maior grau de apinhamento na região anterior de modo significante no gênero masculino. Todas as demais medidas também apresentaram-se aumentadas no gênero masculino, conduzindo a uma conclusão de que é de se esperar a presença de arcos maiores em todos os sentidos neste, embora as mesmas não tenham ocorrido de modo significante.

\section{Relação entre discrepância de tamanho den- tário com os diferentes tipos de oclusão den- tária}

Uma vez evidenciada a não ocorrência de dimorfismo sexual entre a discrepância de tamanho dentário (RAZ12 e RAZ6) dentro dos diferentes grupos analisados, os dois gêneros foram agrupados e com isso, pode-se comparar a possível presença de relação entre os diferentes tipos de más oclusões (Classe I, Classe II e Classe III, além do grupo controle com Oclusão Normal) e a presença, ou não, de discrepância de tamanho dentário.

Embora no Brasil ocorra uma extensa miscigenação racial da população, o que dificulta o estabelecimento preciso da origem étnica dos pacientes, neste estudo procurou-se trabalhar apenas com pacientes leucodermas uma vez que na literatura há relatos de diferenças significantes entre as raças ${ }^{4,11,15,25,32}$, tanto nas dimensões, como nas proporções dos dentes e, em virtude disto, Nie, $\mathrm{Lin}^{21}$ e Ta et al. ${ }^{35}$ sugerem avaliar-se diferentes tipos raciais separadamente, para minimizar quaisquer influências. Smith et al. ${ }^{32}$ relataram também que os leucodermas apresentaram a proporção dentária mais baixa, quando comparados com os 
hispânicos e melanodermas, e que estas diferenças ocorreram em virtude dos segmentos posteriores.

Em relação à razão do somatório de todos os dentes (RAZ12), não foi encontrada diferença significante entre os grupos estudados, ou seja, as médias obtidas para esta medida nos portadores de Oclusão Normal, de Classe I, de Classe II e de Classe III (médias de 91,76\%; 92,13\%; 92,24\% e $91,15 \%$, respectivamente) foram muito próximas, indicando que a relação entre todos os dentes superiores com os inferiores não influencia na ocorrência das más oclusões. Estes resultados corroboram com os achados de Crosby e Alexander ${ }^{7}$, que observaram que nenhum grupo específico de má oclusão (Classe I, Classe II, div. 1 e 2 e Classe III) apresentou significância estatística nas discrepâncias encontradas e também com os resultados encontrados por Freeman et al. ${ }^{11}$, embora não tenham dividido a amostra em grupos específicos de má oclusão. Por outro lado, há relatos na literatura apresentando resultados estatisticamente significantes entre os diferentes tipos de más oclusões e a discrepância de tamanho dentário ${ }^{15,16,21,33}$, sugerindo que esta deve ser um dos fatores importantes na ocorrência das más oclusões, especialmente nas Classes II e III ${ }^{21}$.

Por outro lado, a razão entre o somatório dos dentes anteriores superiores e os anteriores inferiores (RAZ6) apresentou diferença estatisticamente significante entre os grupos estudados, sendo que os valores obtidos para os portadores de Oclusão Normal, de Classe I, de Classe II e de Classe III foram de 78,24\%; 77,14\%; 79,79\% e 79,54\%, respectivamente. $\mathrm{Na}$ interpretação dos resultados, um valor acima de $77,2 \%$, como proposto por Bolton, sugere que o excesso encontrase localizado no arco inferior, ou seja, os dentes ântero-inferiores apresentaram-se aumentados em seu diâmetro mesiodistal, quando comparados com os superiores. De acordo com os resultados deste estudo observou-se que, com exceção dos portadores de Classe I, todos os demais grupos apresentaram um valor acima de $77,2 \%$, indicando então um excesso dentário no arco inferior. De acordo com os valores obtidos neste estudo, o grupo com os portadores de Oclusão Normal não apresentou diferença estatisticamente significante, quando comparado com os demais grupos com má oclusão de Classe I, de Classe II e de Classe III. O grupo com os portadores de Classe I apresentou significância estatística igual ao de Oclusão Normal, mas diferente ao de Classe II e de Classe III, ou seja, como os valores encontrados nos dois últimos foram maiores e com significância, pode-se esperar que os portadores de Classe II e de Classe III apresentem um valor maior para a medida RAZ6 que, clinicamente, implica num maior diâmetro mesiodistal dos dentes ântero-inferiores nestes, quando comparados com os portadores de Classe I. Os grupos com os portadores de Classe II e III apresentaram diferença estatisticamente significante apenas com os de Classe I e foi significantemente igual aos de Oclusão Normal e entre ambos. Portanto, se há ou não presença de discrepância significativa dentro destes grupos individualmente, as mesmas não se manifestaram de modo a causar uma diferença inter-grupos (Oclusão Normal, Classe II e Classe III). Mesmo que tenha ocorrido diferença significativa dentro destes grupos, individualmente, pode-se observar que a predominância foi de excesso no arco inferior, corroborando com os achados de Sperry et al. ${ }^{33}$, Legovic et al. ${ }^{16}$, Freeman et al. ${ }^{11}$ e Klein ${ }^{14}$, embora estes tenham encontrado diferenças significantes entre todos os grupos estudados.

Quando comparou-se o comprimento posterior superior (CPSUP) encontrou-se valores médios de $30,58 \mathrm{~mm} ; 33,74 \mathrm{~mm} ; 32,39 \mathrm{~mm}$ e $31,24 \mathrm{~mm}$ para os grupos com Oclusão Normal, Classe I, Classe II e Classe III, respectivamente. Valores maiores indicam que o comprimento total do arco superior está aumentado e foi observado que os indivíduos com Oclusão Normal apresentaram um arco estatisticamente igual aos com Classe III e estatisticamente diferente aos com Classe I e com Classe II, sendo que estes tiveram essa medida aumentada. O grupo com Classe I apresentou o maior CPSUP entre todos e estatisticamente significante. O grupo com Classe II apresentou diferença estatística dos com Oclusão Normal e com Classe I, sendo 
que seu CPSUP foi maior em relação aos portadores de Oclusão Normal, mas menor do que os portadores de Classe I. O grupo com Classe III apresentou um CPSUP estatisticamente igual aos com Oclusão Normal e com Classe II, mas significantemente menor do que o com Classe I.

$\mathrm{Na}$ comparação do comprimento posterior inferior (CPINF) obteve-se os valores médios de $26,41 \mathrm{~mm} ; 28,59 \mathrm{~mm} ; 27,58 \mathrm{~mm}$ e $26,65 \mathrm{~mm}$ para os grupos com Oclusão Normal, Classe I, Classe II e Classe III, respectivamente. Valores maiores indicam que o comprimento total do arco inferior está aumentado e foi observado que os indivíduos com Oclusão Normal apresentaram um arco estatisticamente igual aos com Classe II e com Classe III e estatisticamente diferente aos com Classe I, sendo que neste essa medida manifestou-se aumentada. Com base nesses dados, pode-se afirmar que nos portadores de Oclusão Normal é de se esperar a presença de arcos inferiores mais curtos do que nos portadores de Classe I e proporcionais aos portadores de Classe II e de Classe III. O grupo com Classe I apresentou diferença estatística dos com Oclusão Normal e com Classe III e foi estatisticamente igual aos com Classe II, sendo que é de se esperar que portadores de má oclusão de Classe I apresentem arcos inferiores mais compridos do que portadores de Oclusão Normal e de Classe III. O grupo com Classe II não apresentou diferença estatisticamente significante com os demais grupos pesquisados. O grupo com Classe III apresentou um CPINF estatisticamente igual aos com Oclusão Normal e com Classe II, mas significantemente menor do que o com Classe I.

Em relação à medida CASUP não foi encontrada diferença significante entre os grupos estudados, ou seja, as médias obtidas nos portadores de Oclusão Normal, Classe I, Classe II e Classe III $(7,95 \mathrm{~mm} ; 8,58 \mathrm{~mm} ; 8,46 \mathrm{~mm}$ e $7,92 \mathrm{~mm}$, respectivamente) indicam que o comprimento anterior do arco superior não apresenta um padrão de comportamento específico, de acordo com os diferentes tipos de más oclusões, bem como nos portadores de Oclusão Normal.

Quando comparou-se o comprimento anterior inferior (CAINF) obteve-se os valores médios de $4,63 \mathrm{~mm} ; 5,22 \mathrm{~mm} ; 5,50 \mathrm{~mm}$ e $4,81 \mathrm{~mm}$ para os grupos com Oclusão Normal, Classe I, Classe II e Classe III, respectivamente. Valores maiores indicam que o comprimento anterior do arco inferior está aumentado e foi observado que os indivíduos com Oclusão Normal apresentaram um arco estatisticamente igual aos com Classe I e com Classe III e estatisticamente diferente aos com Classe II, sendo que neste essa medida foi maior. Com base nesses dados pode-se afirmar que nos portadores de Oclusão Normal é de se esperar a presença arcos inferiores mais curtos, em sua região anterior, do que nos portadores de Classe II. Os grupos com Classe I e com Classe III não apresentaram diferença estatisticamente significante com os demais grupos. O grupo com Classe II teve seu comprimento anterior maior, de modo estatisticamente significante, em relação ao com Oclusão Normal e foi estatisticamente igual aos portadores de Classe I e de Classe III.

$\mathrm{Na}$ comparação da largura anterior superior (LASUP) (com valores médios de $34,53 \mathrm{~mm}$; $35,98 \mathrm{~mm} ; 34,02 \mathrm{~mm}$ e $34,47 \mathrm{~mm}$ para os grupos com Oclusão Normal, Classe I, Classe II e Classe III, respectivamente), da largura anterior inferior (LAINF) (com valores médios de 25,82mm; $26,81 \mathrm{~mm} ; 26,59 \mathrm{~mm}$ e $26,72 \mathrm{~mm}$ para os grupos com Oclusão Normal, Classe I, Classe II e Classe III, respectivamente), da largura posterior superior (LPSUP) (com valores médios de $48,15 \mathrm{~mm} ; 47,89 \mathrm{~mm} ; 47,48 \mathrm{~mm}$ e $48,90 \mathrm{~mm}$ para os grupos com Oclusão Normal, Classe I, Classe II e Classe III, respectivamente) e da largura posterior inferior (LPINF) (com valores médios de $41,86 \mathrm{~mm}$; 41,80mm; 42,39mm e 44,02mm para os grupos com Oclusão Normal, Classe I, Classe II e Classe III, respectivamente) observou-se que não ocorreu nenhuma diferença estatisticamente significante entre essas medidas e os diferentes grupos pesquisados, ou seja, não houve relação entre as larguras dos arcos superiores e inferiores, tanto na região anterior como na posterior, com os diferentes tipos de má oclusão e com os portadores de Oclusão Normal. 
$\mathrm{Na}$ avaliação do índice de irregularidade no arco superior (IIRSUP), que quantifica o apinhamento na região ântero-superior, obteve-se os valores médios de 3,84mm; 10,66mm; 8,66mm e 5,90mm para os grupos com Oclusão Normal, Classe I, Classe II e Classe III, respectivamente. Quanto maior o valor obtido para esta medida significa que há um maior desarranjo dos incisivos e dos caninos em seus respectivos arcos dentários. Foi observado que os indivíduos com Oclusão Normal foram os que apresentaram o menor índice de todos, como esperado. $\mathrm{O}$ grupo com Classe I apresentou o maior IIRSUP entre todos e com significância estatística, indicando que este tipo de má oclusão apresenta maior predominância do apinhamento na região anterior. Os grupos com Classe II e com Classe III foram iguais entre si, mas abaixo do com Classe I. De acordo com a classificação do grau de apinhamento proposta por Little ${ }^{17}$, pode-se afirmar que os portadores de Oclusão Normal apresentaram uma irregularidade mínima, os portadores de Classe I uma irregularidade muito severa, os portadores de Classe II uma irregularidade severa e os portadores de Classe III uma irregularidade moderada para o arco superior.

$\mathrm{Na}$ comparação do índice de irregularidade no arco inferior (IIRINF), que quantifica o apinhamento na região ântero-inferior, obteve-se os valores médios de $3,42 \mathrm{~mm} ; 7,27 \mathrm{~mm} ; 6,25 \mathrm{~mm}$ e $3,80 \mathrm{~mm}$ para os grupos com Oclusão Normal, Classe I, Classe II e Classe III, respectivamente. Seguindo o mesmo tipo de interpretação pode-se afirmar que quanto maior o valor obtido para esta medida significa que há um maior desarranjo dos incisivos e dos caninos em seus respectivos arcos dentários. Não foram realizadas comparações interarcos e seus respectivos grupos de má oclusão mas, de um modo geral, pode-se observar que os valores obtidos para o arco inferior foram menores, em todos os grupos pesquisados, do que no superior, indicando um menor desarranjo. Como esperado os indivíduos com Oclusão Normal foram os que apresentaram o menor índice. $\mathrm{O}$ grupo com Classe I apresentou o maior IIRINF entre to- dos, indicando uma quantidade maior de apinhamento, embora tenha sido estatisticamente igual ao com Classe II e diferente estatisticamente dos grupos com Oclusão Normal e Classe III. O grupo com Classe II foi igual estatisticamente aos grupos com Classe I e com Classe III, e diferente estatisticamente apenas do grupo com Oclusão Normal, indicando que é de se esperar uma maior quantidade de apinhamento na região ântero-inferior nos portadores de Classe II, em relação apenas à Oclusão Normal. O grupo com Classe III foi igual estatisticamente ao com Classe II, mas com diferença estatística entre os grupos com Oclusão Normal e com Classe I, sendo que seus valores estiveram acima do com Oclusão Normal, indicando uma maior quantidade de apinhamento na região ântero-inferior, mas abaixo do com Classe I, indicando que, embora ocorram apinhamentos na região ântero-inferior nestes grupos de má oclusão é de se esperar que estes se manifestem em menor quantidade do que nos portadores de Classe I. Aplicando-se a classificação do grau de apinhamento proposta por Little ${ }^{17}$, pode-se afirmar que os portadores de Oclusão Normal e de Classe III apresentaram uma irregularidade mínima, os portadores de Classe I uma irregularidade severa e os portadores de Classe II uma irregularidade moderada para o arco inferior.

Quando comparou-se o índice de irregularidade "corrigido" no arco superior (IIRCSUP), obteve-se os valores médios de 2,84mm; 8,15mm; $6,62 \mathrm{~mm}$ e $5,83 \mathrm{~mm}$ para os grupos com Oclusão Normal, Classe I, Classe II e Classe III, respectivamente. Quanto maior o valor obtido para esta medida significa que há um maior desarranjo dos incisivos e dos caninos em seus respectivos arcos dentários. Embora não tenham sido feitas comparações entre os índices "corrigido" e "não corrigido", observou-se que todas as medidas "corrigidas" apresentaram-se sistematicamente diminuídas, ou seja, neste grupo a quantidade de apinhamento observado foi menor e isso deveu-se à eliminação da coordenada vertical no instrumento de medição. Analisando-se os resultados obtidos, foi observado que os indivíduos com Oclusão Normal fo- 
ram os que apresentaram o menor índice de todos, como esperado. O grupo com Classe I apresentou o maior IIRCSUP entre todos e com significância estatística. Os grupos com Classe II e com Classe III foram iguais entre si, estatisticamente, e seus valores estiveram acima do com Oclusão Normal, indicando uma maior quantidade de apinhamento na região anterior, mas abaixo do com Classe I. De acordo com a classificação do grau de apinhamento proposta por Little ${ }^{17}$, pode-se afirmar que os portadores de Oclusão Normal apresentaram uma irregularidade mínima, os portadores de Classe I uma irregularidade severa e os portadores de Classe II e de Classe III uma irregularidade moderada para o arco superior.

Quando comparou-se o índice de irregularidade corrigido no arco inferior (IIRCINF), obteve-se os valores médios de 2,61 mm; 4,84mm; 4,45mm e 3,70mm para os grupos com Oclusão Normal, Classe I, Classe II e Classe III, respectivamente. Observou-se, também, que os indivíduos com Oclusão Normal foram os que apresentaram o menor índice de todos, embora sem significância estatística quando comparado com os portadores de Classe III e diferente estatisticamente dos demais. O grupo com Classe I apresentou o maior IIRCINF entre todos, indicando uma quantidade maior de apinhamento, embora tenha sido estatisticamente igual ao com Classe II e diferente estatisticamente dos grupos com Oclusão Normal e Classe III. O grupo com Classe II foi igual estatisticamente aos grupos com Classe I e com Classe III, e diferente estatisticamente apenas do grupo com Oclusão Normal, indicando que é de se esperar uma maior quantidade de apinhamento na região ântero-inferior nos portadores de Classe II, em relação à Oclusão Normal. O grupo com Classe III foi igual estatisticamente aos grupos com Classe II e com Oclusão Normal, mas com diferença estatística com o grupo com Classe I, sendo que seus valores estiveram abaixo do com Classe I, indicando uma menor quantidade de apinhamento na região ântero-inferior e situado entre os portadores de Oclusão Normal (acima) e os com Classe II (abaixo). Aplicando-se a classificação do grau de apinhamento proposta por Little ${ }^{17}$, podese afirmar que os portadores de Oclusão Normal e de Classe III apresentaram uma irregularidade mínima e os portadores de Classe I e de Classe II uma irregularidade moderada no arco inferior.

Quando da análise de todos os índices de irregularidade (IIRSUP, IIRINF, IIRCSUP e IIRCINF), pode-se observar uma diferença nos valores obtidos entre os índices "corrigidos" (IIRCSUP e IIRCINF) e os "não corrigidos" (IIRSUP e IIRINF). Este fato nos leva a ressaltar a importância de se realizar uma adequação na utilização do Digitalizador MICROSCRIBE-3DX, quando forem necessários a avaliação e o estudo bidimensional de estruturas tridimensionais, uma vez que poder-se-á estar embutindo coordenadas e, conseqüentemente valores, que poderão interferir nos resultados obtidos.

\section{Especificidade na localização da discrepância de tamanho dentário de acordo com os gru- pos de oclusão dentária}

Após determinada a ocorrência de diferenças entre os grupos, especialmente para as medidas RAZ12 (Fig. 6) e RAZ6 (Fig. 7), procurou-se estabelecer se há uma especificidade na localização das discrepâncias, em cada grupo específico de oclusão dentária.

A maioria dos trabalhos encontrados na literatura relatam a ocorrência de discrepância de tamanho dentário nos diferentes tipos de más oclusões ${ }^{15,16,21,33}$, sendo que Sperry et al. ${ }^{33}$ compararam portadores de Classe III e Classe I, onde constataram um maior número de casos com excesso mandibular, sugerindo ainda que a magnitude do excesso era maior nos portadores de prognatismo mandibular. Com resultados similares, Araújo e Wilhelm ${ }^{1}$ observaram excesso no arco inferior, em portadores de Classe I e Classe II, tanto na região anterior como em todo o arco. Legovic et al. ${ }^{16}$ encontraram um predomínio de excesso ântero-inferior nos portadores de Classe I e de Classe II, div. 1 e div. 2, bem como, Klein ${ }^{14}$ relatou um caso clínico com Classe II, div.1, apresentando também excesso no arco inferior. De um modo geral e baseado nos 
relatos encontrados na literatura, pode-se observar que não houve uma especificidade na ocorrência dos excessos e estes tiveram um predomínio de manifestação no arco inferior, independentemente da má oclusão.

No presente estudo, observou-se que em relação à razão do somatório de todos os dentes (RAZ12) não foi encontrada diferença significante entre os grupos estudados, ou seja, as médias obtidas para esta medida nos portadores de Oclusão Normal, Classe I, Classe II e Classe III (médias de 91,76\%; 92,13\%; 92,24\% e 91,15\%, respectivamente) indicam que a relação entre todos os dentes superiores com os inferiores não influenciou na ocorrência das más oclusões.

Nas avaliações intragrupos, em relação à medida RAZ12, de acordo com a tabela 3, figura 6 e figura 7 foram analisadas as distribuições das freqüências de normalidade e não normalidade, sendo que a não normalidade refere-se aos excessos dentários com significância clínica, ou seja, aqueles situados acima de dois desvios-padrão $(1,91$ x $2=3,82$ ) e a normalidade também pode expressar excessos superior ou inferior, mas situada dentro de dois desvios-padrão. Observou-se que no grupo com Oclusão Normal as freqüências dos excessos, além da variação de normalidade, foram estatisticamente iguais entre si, ou seja, ocorreu um equilíbrio na distribuição dos excessos entre os arcos superiores e inferiores, embora tenham ocorrido, de modo significante, em menor freqüência do que as condições de excesso dentro da normalidade, que foi predominante neste grupo. Do total de 41 indivíduos portadores de Oclusão Normal, observou-se a ocorrência de $46,3 \%$ de excesso no arco superior, sendo que deste total 2,4\% foram além da variação de normalidade e 53,7\% de excesso no arco inferior, sendo que deste total $13,2 \%$ estiveram situados além da variação de normalidade.

No grupo com Classe I, as freqüências de normalidade e não normalidade apresentaram diferença estatística entre si, indicando que os excessos ocorreram de modo significante dentro deste grupo de má oclusão. Analisando os valores obtidos, pode-se observar que houve um predomínio das medidas dentro da normalidade, com $88,6 \%$ da ocorrência total, sendo que $11,4 \%$ deste grupo apresentou excesso, além da variação de normalidade, no arco inferior e nenhum indivíduo pesqui-

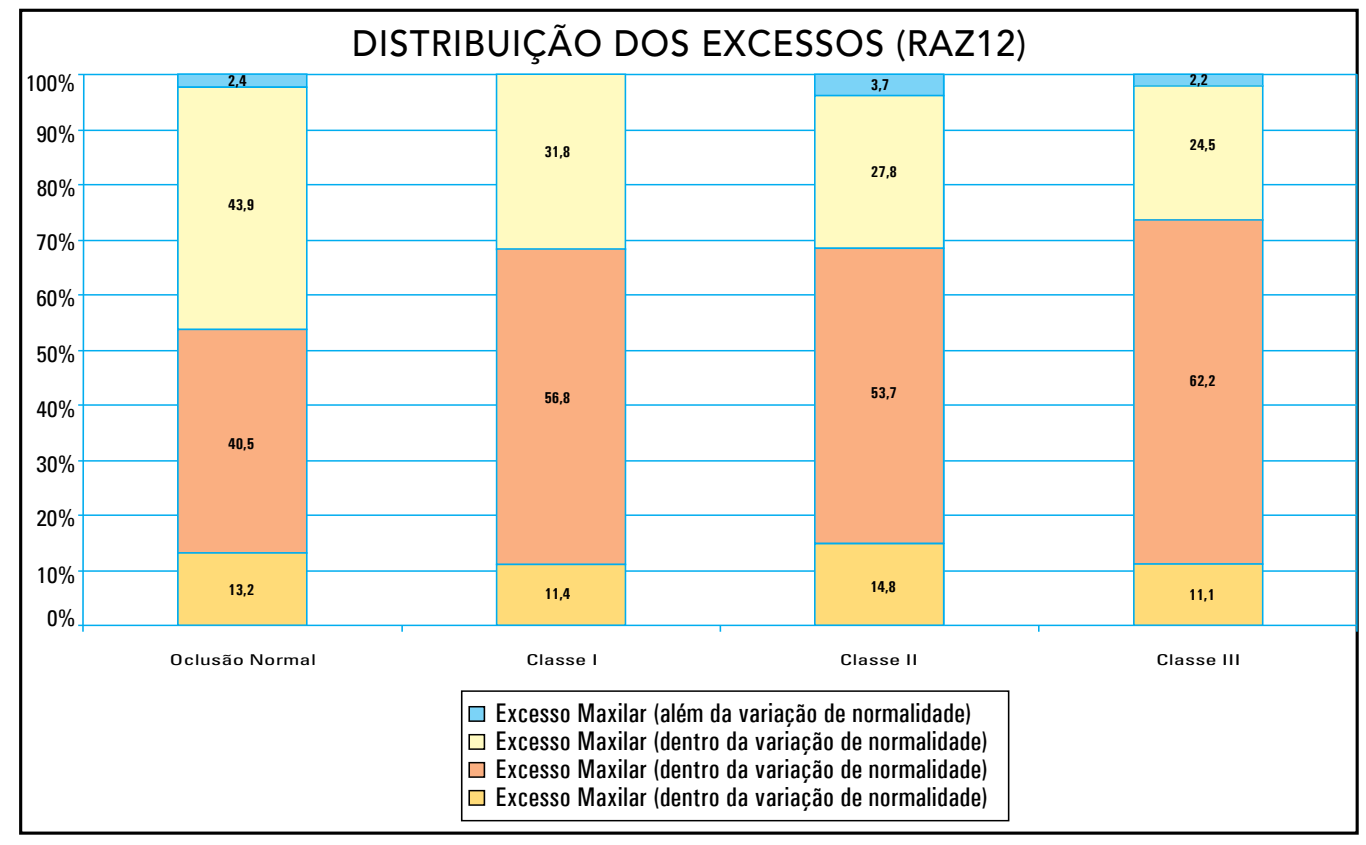

FIGURA 6 - Distribuição dos excessos superior e inferior (RAZ12). 
sado teve seu arco superior com excesso além desta variação. Do total de 44 indivíduos portadores de má oclusão de Classe I, observou-se a ocorrência de $31,8 \%$ de excesso no arco superior, sendo que deste total nenhum foi além da variação de normalidade e $68,2 \%$ de excesso no arco inferior, sendo que deste total $11,4 \%$ estiveram situados além da variação de normalidade, ou seja, apresentaram excesso com significância clínica.

No grupo com Classe II as freqüências dos excessos, além da variação de normalidade, foram estatisticamente iguais entre si, ou seja, ocorreu um equilíbrio na distribuição dos excessos entre os arcos superiores e inferiores, embora tenham ocorrido, de modo significante, em menor freqüência do que as condições de excesso dentro da normalidade, que foi predominante neste grupo, semelhante ao ocorrido com o grupo de Oclusão Normal. Analisando os valores obtidos, pode-se observar que houve um predomínio das medidas dentro da normalidade, com $81,5 \%$ da ocorrência total, sendo que $14,8 \%$ apresentou excesso, além da variação de normalidade, no arco inferior e 3,7\% deste grupo apresentou excesso, além da variação de normalidade, no arco superior.
Do total de 54 indivíduos portadores de má oclusão de Classe II, observou-se a ocorrência de 31,5\% de excesso no arco superior, sendo que deste total $3,7 \%$ foi além da variação de normalidade e $68,5 \%$ de excesso no arco inferior, sendo que deste total 14,8\% estiveram situados além da variação de normalidade, ou seja, apresentaram excesso com significância clínica.

Similarmente ao ocorrido com os portadores de Oclusão Normal e de Classe II, no grupo com Classe III as freqüências dos excessos, além da variação de normalidade, foram estatisticamente iguais entre si, ou seja, ocorreu um equilíbrio na distribuição dos excessos entre os arcos superiores e inferiores, embora tenham ocorrido, de modo significante, em menor freqüência do que as condições de excesso dentro da normalidade, que foi predominante neste grupo. Analisando os valores obtidos, pode-se observar que também houve um predomínio das medidas dentro da normalidade, com $86,7 \%$ da ocorrência total, sendo que $11,1 \%$ apresentou excesso, além da variação de normalidade, no arco inferior e 2,2\% deste grupo apresentou excesso, além da variação de normalidade, no arco superior. Do total de 45 indivíduos porta-

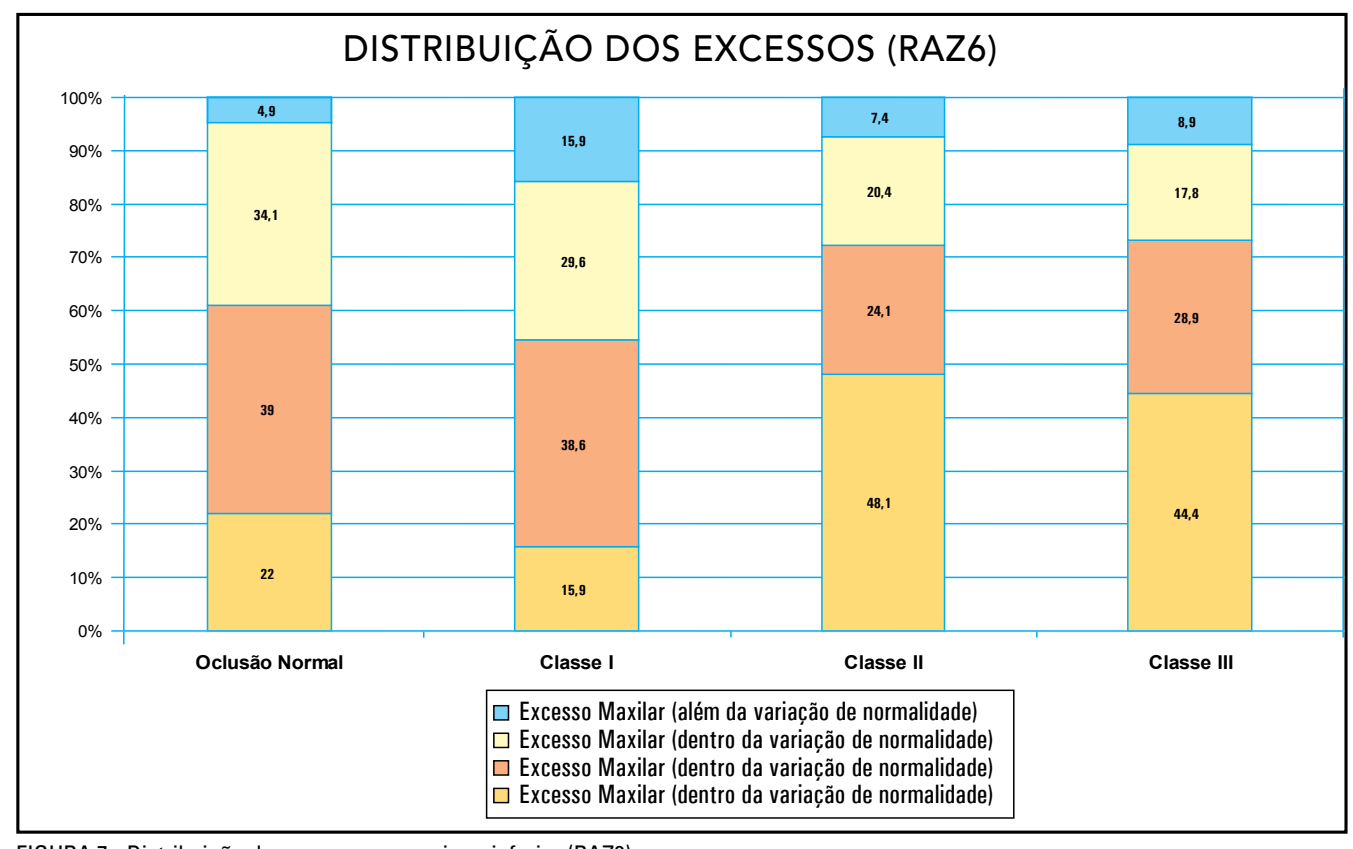

FIGURA 7 - Distribuição dos excessos superior e inferior (RAZ6). 
dores de má oclusão de Classe III, observou-se a ocorrência de $26,7 \%$ de excesso no arco superior, sendo que deste total 2,2\% foi além da variação de normalidade e $73,3 \%$ de excesso no arco inferior, sendo que deste total $11,1 \%$ estiveram situados além da variação de normalidade, ou seja, apresentaram excesso com significância clínica.

Em relação à razão do somatório dos dentes anteriores (RAZ6), observou-se uma diferença estatisticamente significante entre os grupos estudados, sendo que as médias obtidas para os portadores de Oclusão Normal, Classe I, Classe II e Classe III foram de 78,24\%, 77,14\%, 79,79\% e $79,54 \%$, respectivamente, indicando uma possivel interferência da relação dos dentes anteriores nos diferentes grupos estudados, o que foi determinado pelas avaliações intragrupos.

Para a medida RAZ6, de acordo com a tabela 3 e a figura 7, foram analisadas as distribuições das freqüências de normalidade e não normalidade, sendo que a não normalidade refere-se aos excessos dentários com significância clínica, ou seja, aqueles situados acima de dois desvios-padrão $(1,65 \times 2=3,3)$ e a normalidade também pode expressar excessos superior ou inferior, mas situada dentro de dois desvios-padrão. Observou-se que, no grupo com Oclusão Normal, as freqüências de normalidade e não normalidade, tanto aquém como além dos valores, apresentaram diferença estatística entre si, indicando que os excessos ocorreram de modo significante dentro deste grupo pesquisado. Analisando os valores pode-se observar que houve um predomínio das medidas dentro da normalidade, com $73,1 \%$ da ocorrência total, sendo que $22 \%$ deste grupo apresentou excesso, além da variação de normalidade, no arco inferior e apenas 4,9\% teve seu arco superior com excesso além desta variação. Do total de 41 indivíduos com Oclusão Normal, observou-se a ocorrência de $39 \%$ de excesso no arco superior, sendo que deste total $4,9 \%$ foi além da variação de normalidade e $61 \%$ de excesso no arco inferior, sendo que deste total $22 \%$ estiveram situados além da variação de normalidade, ou seja, apresentaram excesso com significância clínica. De acordo com estes dados pode-se afirmar que os valores propostos por Bolton ${ }^{5}$, para a RAZ6, não se enquadraram nesta amostra de Oclusão Normal, corroborando com os valores encontrados por Heusdens et al. ${ }^{12}$

No grupo com Classe I as freqüências dos excessos, além da variação de normalidade, foram estatisticamente iguais entre si, ou seja, ocorreu um equilíbrio na distribuição dos excessos entre os arcos superiores e inferiores, embora tenham ocorrido, de modo significante, em menor freqüência do que as condições de excesso dentro da normalidade, que foi predominante neste grupo. Analisando os valores pode-se observar que houve um predomínio das medidas dentro da normalidade, com $68,2 \%$ da ocorrência total, sendo que $15,9 \%$ apresentou excesso, além da variação de normalidade, no arco inferior e 15,9\% deste grupo apresentou excesso, além da variação de normalidade, no arco superior. Do total de 44 indivíduos portadores de má oclusão de Classe I, observou-se a ocorrência de $45,5 \%$ de excesso no arco superior, sendo que deste total $15,9 \%$ foi além da variação de normalidade e $54,5 \%$ de excesso no arco inferior, sendo que deste total 15,9\% estiveram situados além da variação de normalidade, ou seja, apresentaram excesso com significância clínica.

No grupo com Classe II as freqüências dos excessos, além da variação de normalidade, foram estatisticamente diferentes entre si, sendo que teve um predomínio na ocorrência dos excessos no arco inferior, embora este tenha sido estatisticamente igual as condições de excesso dentro da normalidade que, por sua vez, também foi diferente estatisticamente dos excessos no arco superior, apresentado-se aumentada. Analisando os valores obtidos, pode-se observar que houve um maior valor para as medidas além da normalidade, no arco inferior, com $48,1 \%$ da ocorrência total, sendo que $44,5 \%$ esteve dentro da variação de normalidade e 7,4\% deste grupo apresentou excesso, além da variação de normalidade, no arco superior. Do total de 54 indivíduos portadores de má oclusão de Classe II, observou-se a ocorrência de 27,8\% de excesso no arco superior, sendo que deste total $7,4 \%$ foi além da variação de normalidade e $72,2 \%$ 
de excesso no arco inferior, sendo que deste total 48,1\% estiveram situados além da variação de normalidade, ou seja, apresentaram excesso com significância clínica.

Similarmente ao ocorrido no grupo com Classe II, no com Classe III as freqüências dos excessos, além da variação de normalidade, foram estatisticamente diferentes entre si, sendo que também teve um predomínio na ocorrência dos excessos no arco inferior, embora este tenha sido estatisticamente igual às condições de excesso dentro da normalidade que, por sua vez, também foi diferente estatisticamente dos excessos no arco superior, apresentado-se aumentada. Analisando os valores obtidos, pode-se observar que houve um maior valor para as medidas dentro da variação de normalidade, com $46,7 \%$ da ocorrência total, sendo que $44,4 \%$ apresentou excesso no arco inferior, além da variação de normalidade e 8,9\% deste grupo apresentou excesso, além da variação de normalidade, no arco superior. Do total de 45 indivíduos portadores de má oclusão de Classe III, observou-se a ocorrência de $26,7 \%$ de excesso no arco superior, sendo que deste total 8,9\% foi além da variação de normalidade e $73,3 \%$ de excesso no arco inferior, sendo que deste total $44,4 \%$ estiveram situados além da variação de normalidade, ou seja, apresentaram excesso com significância clínica.

De um modo geral, a medida RAZ12 indicou que os grupos estudados foram iguais estatisticamente, apresentando um predomínio de excesso no arco inferior, sendo este mais evidente nos portadores de Classe III, Classe II, Classe I e Oclusão Normal, sucessivamente. Na avaliação intragrupo, os grupos com os portadores de Oclusão Normal, Classe I e Classe II apresentaram resultados semelhantes estatisticamente, uma vez que os excessos, além da variação de normalidade, foram iguais entre si, diferindo apenas da ocorrência de excessos dentro da variação de normalidade. Apenas os portadores de Classe I tiveram um excesso significante no arco inferior, além da variação de normalidade, maior do que no arco superior, sendo que este não teve nenhum caso registrado.
Por outro lado, a medida RAZ6 indicou que os grupos estudados apresentaram diferenças significantes entre os mesmos, prevalecendo também o excesso no arco inferior, sendo que este foi mais evidente nos portadores de Classe II, Classe III, Oclusão Normal e Classe I, sucessivamente. O excesso no arco inferior, além da variação de normalidade, foi predominante, quando comparado com o arco superior, nos portadores de Classe II, Classe III e também com Oclusão Normal. Diferentemente, na Classe I a distribuição entre os excessos superiores e inferiores foi eqüitativa.

\section{Influência da discrepância de tamanho den- tário na forma do arco e no posicionamento dentário}

Outro questionamento inicial da pesquisa foi se as discrepâncias de tamanho dentário, representadas pelas medidas RAZ12 e RAZ6, exercem algum tipo de influência sobre as demais medidas analisadas. Para tal aplicou-se a regressão linear para a RAZ12 (Tab. 4) e para a RAZ6 (Tab. 5), separadamente.

Um aspecto importante que deve ser considerado é que a forma dos arcos e o posicionamento dentário são influenciados por fatores ambientais e devido a isso, a possível influência da discrepância de tamanho dentário nestes exige uma interpretação mais cuidadosa.

De acordo com a tabela 4 , analisou-se primeiramente a possivel influência da RAZ12 sobre os comprimentos posterior e anterior, as larguras posterior e anterior e o posicionamento dentário na região anterior, em ambos os arcos. Constatou-se que ocorreram valores com significância estatística para várias medidas como CPINF, LASUP, LAINF, LPINF, IIRSUP, IIRCSUP e IIRCINF, mas como o coeficiente de determinação $\left(R^{2}\right)$ foi inexpressivo para todas as medidas, não foi possível afirmar que a RAZ12 exerceu algum tipo de influência efetiva sobre todas as que obtiveram significância estatística.

Do mesmo modo e de acordo com a tabela 5, analisou-se a possivel influência da RAZ6 sobre as dimensões e o apinhamento. Constatou-se que 
ocorreram valores com significância estatística para as medidas CPSUP e CASUP, mas como o coeficiente de determinação $\left(\mathrm{R}^{2}\right)$ também foi inexpressivo para todas as medidas, assim como para a RAZ12, não foi possível afirmar que a RAZ6 exerceu algum tipo de influência efetiva sobre todas as que obtiveram significância estatística.

\section{CONCLUSÕES}

Baseado na amostra estudada, na condição em que foi desenvolvido este estudo e de acordo com os resultados apresentados, parece-nos lícito concluir que:

1) Não ocorreu dimorfismo sexual entre as discrepâncias de tamanho dentário e os diferentes tipos de oclusão dentária.

2) As proporções estabelecidas por Bolton não se aplicaram perfeitamente ao grupo de Oclusão Normal, sugerindo que novos estudos devam ser realizados com o intuito de se estabelecer um padrão para brasileiros leucodermas.
3) Na Oclusão Normal, Classe I, Classe II e Classe III, ocorreu um predomínio de excesso dentário total (RAZ12) no arco inferior, em relação ao arco superior.

4) $\mathrm{Na}$ Classe I houve uma igualdade na distribuição de excesso dentário anterior (RAZ6) nos arcos superior e inferior.

5) Na Oclusão Normal, Classe II e Classe III, ocorreu um predomínio de excesso dentário anterior (RAZ6) no arco inferior, em relação ao arco superior.

6) Os excessos dentários não contribuíram para a ocorrência das más oclusões.

7) As discrepâncias total e anterior (RAZ12 e RAZ6) não se correlacionaram significantemente com as larguras anterior e posterior e nos comprimentos anterior e posterior dos arcos, bem como no posicionamento dos dentes anteriores.

Enviado em: Junho de 2003 Revisado e aceito: Setembro de 2003

\title{
Bolton tooth size discrepancy in normal occlusion and in different types of malocclu-
} sions and its relationship to arch form and tooth positioning

\begin{abstract}
The general purpose of this study was to evaluate tooth size discrepancy in normal occlusion and in different malocclusion types and its relationship to measurements which determine arch form and anterior tooth positioning. One hundred and eighty five sets of casts of leucoderms were divided into four groups: Group 1 (consisted of 41 pairs of models with Normal Occlusion, 20 males and 21 females); Group 2 (consisted of 44 pairs of models with Class I malocclusion, 22 males and 22 females); Group 3 (consisted of 54 pairs of models with Class II, div. 1, malocclusion, 28 males and 26 females) and Group 4 (consisted of 46 pairs of models with Class III malocclusion, 23 males and 23 females). No sexual dimorphism was observed between tooth size discrepancies and different types of dental occlusion; the proportions stated by Bolton were not applied to the Normal Occlusion group; in Normal Occlusion, Class I, Class II and Class III there was an overall ratio excess in the lower arch; in Class I there was an equal anterior excess distribution in upper and lower arches; in Normal Occlusion, Class II and Class III there was a prevalent incidence of anterior ratio excess in lower arch; upper arch excess did not contribute to malocclusion occurrence and overall and anterior discrepancies did not interfere with arch width and length, as well as with anterior tooth positioning
\end{abstract}

Key words: Tooth size discrepancy. Arch dimensions. Normal occlusion. Malocclusion. Incisor irregularity. 


\section{REFERÊNCIAS}

1. ARAÚJO, L. G.; WILHELM, R. S. Incidência da discrepância de Bolton. RGO, Porto Alegre, v. 34, n. 2, p. 160-168, mar./abr. 1986.

2. ARYA, B. S. et al. Relation of sex and occlusion to mesiodistal tooth size. Am J Orthod, St. Louis, v. 66, no. 5, p. 479-486, Nov. 1974.

3. BALLARD, M. L. A fifth column within normal dental occlusion. Am J Orthod, St. Louis, v. 42, p.116-124, 1956.

4. BISHARA, S. E. et al. Comparisons of mesiodistal and buccolingual crown dimensions of the permanent teeth in three populations from Egypt, México, and the United States. Am J Orthod Dentofacial Orthop, St. Louis, v. 96, no. 5, p. 416-422, Nov. 1989.

5. BOLTON, W. A. Disarmony in tooth size and its relation to the analysis and treatment of malocclusion. Am J Orthod, St. Louis, v. 28 , no. 3, p.113-130, July 1958 .

6. BOLTON, W. A. The clinical aplication of a tooth-size analysis. Am J Orthod, St. Louis, v. 48, no. 7, p. 504-529, July 1962.

7. CROSBY, D. A.; ALEXANDER, C.G. The occurrence of a toothsize discrepancies among differents malocclusion groups. Am J Orthod Dentofacial Orthop, St. Louis, v. 95, no. 6, p. 457-461. Jan. 1991.

8. DORIS, J. M.; BERNARD, B. W.; KUFTINEC, M. M. A biometric study of a tooth-size and dental crowding. Am J Orthod, St. Louis, v. 79, no. 3, p. 326-336, Mar. 1981.

9. FASTLICHT, J. Crowding of mandibular incisors. Am J Orthod, St. Louis, v. 58, no. 2, p.153-163, Aug. 1970.

10. FIELDS, H. W. Orthodontic-restorative treatment for relative mandibular anterior excess tooth-size problems. Am J Orthod, St. Louis, v. 79, no. 2, p. 176-183, Feb. 1981.

11. FREEMAN, J. E.; MASKERONI, A. J.; LORTON, L. Frequence of Bolton tooth-size discrepancies among orthodontic patients. Am J Orthod Dentofacial Orthop, St. Louis, v. 110, no. 1, p. 24-27, July 1996.

12. HEUSDENS, M.; DERMAUT, L.; VERBEECK, R. The effect of tooth size discrepancy on occlusion: An experimental study. Am J Orthod Dentofacial Orthop, St. Louis, v. 117, no. 2, p. 184-191, Feb. 2000.

13. HUNTER, W. S.; PRIEST, W. R. Errors and discrepancies in measurements of tooth-size. J Dent Res, Washington D.C., v. 39, no. 2, p. 495-514, Mar./Apr. 1960.

14. KLEIN, D. J. The mandibular central incisor, an extraction option. Am J Orthod Dentofacial Orthop, St. Louis, v. 111, no. 3, p. 253-259, Mar. 1997.

15. LAVELLE, C. L. B. Maxillary and mandibular tooth size in different racial groups and in different occlusion categories. Am J Orthod Dentofacial Orthop, St. Louis, no. 6, p. 29-37, Jan. 1972.

16. LEGOVIC, M.; CEHIC, A.; BAJAN, M. Indici di Bolton nelle anomalie $\mathrm{Cl} I \mathrm{I} / 1, \mathrm{Cl} I \mathrm{l} / 2$ e $\mathrm{Cl}$ I com afollamento frontale. Minerva Stomatol, Torino, v. 38, no. 6, p. 679-682, Giugno 1989.

17. LITTLE, R. M. The irregularity Index: a quantitative score of mandibular anterior alignment. Am J Orthod, St. Louis, v. 68, no. 5, p. 554-563, Nov. 1975.

18. LUNDSTRÖM, A. Intermaxillary tooth widht ratio and tooth alignment and occlusion Acta Odontol Scand, Oslo, v. 12, no. 4, p. 265-292, Apr. 1954

19. LUNDSTRÖM, A. Intermaxillary tooth widht ratio analysis. Eur J Orthod, London, v. 3, p. 285-287, 1981.

20. NEFF, C. W. The size relationship between the maxillary and mandibular anterior segments of the dental arch. Angle Orthod, Appleton, v. 27, no. 3, p.138-147, July 1957.

21. NIE, Q.; LIN, J. Comparasion of intermaxillary tooth size discrepancies among different malocclusion groups. Am J Orthod Dentofacial Orthop, St. Louis, v. 116, no. 5, p. 539-544, Nov. 1999.

22. PECK, H.; PECK, S. A Index for assessing tooth shape deviations as applied to the mandibular incisors. Am J Orthod, St Louis, v. 61, no. 4, p. 384-401, Apr. 1972.
23. PINZAN, A.; MARTINS, D. R.; FREITAS, M. R. Análise da discrepância de tamanho dentário de Bolton. Ortodontia, São Paulo, v. 24, n. 1, p. 61-64, Jan./Abr. 1991.

24. RAKOSI, T.; JONAS, I.; GRABER, T. M. Study cast analysis. In: _. Color Atlas of Dental Medicine-Orthodontic-Diagnosis. Stuttgart: Vierlag, 1993. p. 207-235.

25. RICHARDSON, E. R.; MALHOTRA, S. K. Mesiodistal crown dimensions of the permanent dentition of american negroes. Am J Orthod, St. Louis, v. 68, no. 2, p. 157-164, Aug. 1975.

26. SAATÇI, P.; YUKAY, TH. The effect of premolar extractions on tooth-size discrepancy. Am J Orthod Dentofacial Orthop, St. Louis, v. 111, no. 4, p. 428-434, Apr. 1997.

27. SANIN, C.; SAVARA, B. S. An analysis of permanent mesiodistal crown size. Am J Orthod, St. Louis, v. 59, no. 5, p. 488-500, May 1971.

28. SCHIRMER, V. R.; WILSHIRE, W. A. Manual and computer-aided space analysis: A comparative study. Am J Orthod Dentofacial Orthop, St. Louis, v. 112, no. 6, p. 676-680, Dec.1997.

29. SHELLHART, W. C. et al. Reability of the bolton tooth-size analysis when applied to crowded dentitions. Angle Orthod, Appleton, v. 65, no. 5, p. 327-334, Jan. 1995.

30. SHERIDAN, J. J.; HASTINGS, J. Air - rotor stripping and lower incisor extraction treatement. J Clin Orthod, Boulder, v. 26, no. 1, p. 18-22, Jan. 1992.

31. SMITH, R. J.; DAVIDSON, W. M.; GIPE, D. P. Incisor shape and incisor crowding:A re-evaluation of the Peck and Peck ratio. Am J Orthod, St Louis, v. 82, no. 3, p. 231-235, Sept. 1982.

32. SMITH, S. S. et al. Interarch tooth size relationships of 3 populations: "Does Bolton's analysis apply?". Am J Orthod Dentofacial Orthop, St Louis, v. 117, no. 2, p. 169-174, Feb. 2000.

33. SPERRY, T. P. et al. Tooth-size discrepancy in mandibular prognatism. Am J Orthod, St. Louis, v. 72, no. 2, p. 183-190, Aug. 1977.

34. STEYN, C. L.; HARRIS, A. P.; DU PREEZ, R. J. Anterior arch circumference adjustement - how much? Angle Orthod, Appleton, v. 66, no. 6, p. 457-462, Aug. 1995.

35. TA, T. A.; LING, J. Y. K.; HÄGG, U. Tooth-size discrepancies among different occlusion groups of southern Chinese children. Am J Orthod Dentofacial Orthop, St. Louis, v. 120, no. 5, p. 556-558, Nov. 2001.

36. TAYER, B. H. The asymmetric extraction decision. Angle Orthod, Appleton, v. 62, no. 4, p. 291-297, Winter 1992.

37. TUVERSON, D. L. Anterior interocclusal relations. Part I. Am J Orthod, St. Louis, v. 78, no. 4, p. 361-370, Oct. 1980.

38. TUVERSON, D. L. Anterior interocclusal relations. Part II. Am J Orthod, St. Louis, v. 78, no. 4, p. 371-393, Oct. 1980.

39. YAMADA, A. et al. A study of reliability in three dimensional measurement of a dental casts. Aichi Gakuin Daigaku Shigakkai Shi, Nagoya, v. 46, no. 1, p. 18-31, Mar. 1987.

40. WISE, R. J.; NEVINS, M. Anterior tooth-size analysis (Bolton Index). How to determine anterior diastema closure. Int J Periodontics Restorative Dent, Chicago, v. 8, no. 6, p. 8-23, 1988.

41. WOODWORTH, D. A.; SINCLAIR, P. M.; ALEXANDER, R. G. Bilateral congenital absence of maxillary lateral incisors: a craniofacial and dental cast analysis. Am J Orthod, St. Louis, v. 87, no. 4 , p. 280-293, Apr. 1985.

\author{
Endereço para correspondência \\ Luiz Sérgio Carreiro \\ Rua Pará, 1122, sala 61 \\ Londrina/PR \\ CEP: $86010-450$ \\ E-mail: cls@dilk.com.br
}

